\title{
Ice phase in altocumulus clouds over Leipzig: remote sensing observations and detailed modeling
}

\author{
M. Simmel, J. Bühl, A. Ansmann, and I. Tegen \\ TROPOS, Leibniz Institute for Tropospheric Research, Permoser Str. 15, 04318 Leipzig, Germany \\ Correspondence to: M. Simmel (simmel@tropos.de)
}

Received: 19 December 2014 - Published in Atmos. Chem. Phys. Discuss.: 19 January 2015

Revised: 24 August 2015 - Accepted: 9 September 2015 - Published: 24 September 2015

\begin{abstract}
The present work combines remote sensing observations and detailed cloud modeling to investigate two altocumulus cloud cases observed over Leipzig, Germany. A suite of remote sensing instruments was able to detect primary ice at rather high temperatures of $-6^{\circ} \mathrm{C}$. For comparison, a second mixed phase case at about $-25^{\circ} \mathrm{C}$ is introduced. To further look into the details of cloud microphysical processes, a simple dynamics model of the Asai-Kasahara (AK) type is combined with detailed spectral microphysics (SPECS) forming the model system AK-SPECS. Vertical velocities are prescribed to force the dynamics, as well as main cloud features, to be close to the observations. Subsequently, sensitivity studies with respect to ice microphysical parameters are carried out with the aim to quantify the most important sensitivities for the cases investigated.

For the cases selected, the liquid phase is mainly determined by the model dynamics (location and strength of vertical velocity), whereas the ice phase is much more sensitive to the microphysical parameters (ice nucleating particle (INP) number, ice particle shape). The choice of ice particle shape may induce large uncertainties that are on the same order as those for the temperature-dependent INP number distribution.
\end{abstract}

\section{Introduction}

According to Warren et al. (1998a, b) altocumulus and altostratus clouds together cover $22 \%$ of the Earth's surface. For single-layered altocumulus clouds, observations by Bühl et al. (2013) show the typical feature with a maximum of liquid water in the upper part of the cloud (increasing with height) and an ice maximum in the lower part of the cloud, mostly below liquid cloud base down in the virgae; this was previously reported from Fleishauer et al. (2002) and Carey et al. (2008). Fleishauer et al. (2002) also emphasized a lack of significant temperature inversions or wind shears as a major feature of these clouds. Kanitz et al. (2011) show that the ratio of ice-containing clouds increases with decreasing temperature. However, the numbers are different for different locations with similar dynamics but with different aerosol burden, e.g., at northern and southern midlatitudes, underlining the question for the influence of ice-nucleating particles (INPs). The observations with the highest temperatures are close to the limit at which the best atmospheric ice nuclei are known to nucleate ice in the immersion mode. This can only be attributed to the aerosol particles that are formed out of or at least contain biological material such as bacteria (Hartmann et al., 2013), fungi, or pollen. This is corroborated by the review of Murray et al. (2012) stating that only biological particles are known to form ice above $-15^{\circ} \mathrm{C}$. However, these observations are from laboratory studies and it is still unclear whether or to what extent these extremely efficient ice nuclei are abundant in the atmosphere, especially above the boundary layer. One idea is that freezing is caused by soil dust with biological particles dominating the freezing behavior (O'Sullivan et al., 2014), which could explain on the one hand the atmospheric abundance of biological material and on the other hand the relatively high freezing temperatures above $-15^{\circ} \mathrm{C}$ of ambient measurements. Seeding from ice clouds above can be excluded for the cases presented, which means that ice has formed at the cloud temperatures observed.

Ice nucleation still is a large source of uncertainty in cloud modeling. Recently, several studies use combinations of vertically fine-resolved models with rather detailed representa- 
tion of the ice nucleation processes. Often, wave clouds are used as comparison since they represent rather ideal conditions when they are not influenced by ice seeding from layers above. Field et al. (2012) applied a 1-D kinematic model with bulk microphysics but prognostic INPs. Eidhammer et al. (2010) use a Langrangian parcel model for the comparison of the ice nucleation schemes of Phillips et al. (2008) and DeMott et al. (2010) under certain constraints. A 1-D column model with a very detailed 2-D spectral description of liquid and ice phase is employed by Dearden et al. (2012). Sun et al. (2012) used a 1.5-D model with spectral microphysics for shallow convective clouds for a sensitivity study of immersion freezing due to bacteria and its influence on precipitation formation.

Most ice microphysics descriptions are lacking in models from the fact that ice nuclei are not represented as a prognostic variable. These models diagnose the number of ice particles based on thermodynamical parameters such as temperature and humidity (Meyers et al., 1992) and are, therefore, not able to consider whether INPs were already activated at previous time steps in the model.

However, despite its important contribution, ice nucleation does not determine the entire microphysics of mixed-phase clouds alone. It is rather the complex transfer between the three phases of water: water vapor, liquid water and ice described by the Wegener-Bergeron-Findeisen (WBF) mechanism (Wegener, 1911; Bergeron, 1935; Findeisen, 1938). It is well-known that due to the different saturation pressures of water vapor with respect to liquid water and ice, a mixedphase cloud is in a non-equilibrium state that, nevertheless, may lead to a quasi-steady existence (Korolev and Field, 2008). The main drivers for this phase transfer are vertical velocity (leading to supersaturation and subsequent droplet formation) and ice particle formation and growth (WBF starts) leading to sedimentation of the typically fast growing ice particles (WBF ends due to removal of ice). The motivation of this work is to shed more light on the relative contributions of the different processes involved in these complex interactions.

The paper is structured as follows. Section 2 describes the remote sensing observations of two mixed-phase altocumulus cloud cases above Leipzig. The dynamical model, as well as the process descriptions and initial data used for this study, is specified in Sect. 3. Section 4 refers to changes in the dynamic parameters of the model to identify base cases, which describe the observations sufficiently well to perform sensitivity studies with respect to microphysical parameters. The results for those sensitivity studies are presented in Sect. 5 and Sect. 6 closes with a discussion of the results.

\section{Remote sensing observations}

Altocumulus and altostratus clouds are regularly observed with the Leipzig Aerosol and Cloud Remote Observa- tions System (LACROS) at the Leibniz Institute for Tropospheric Research (TROPOS). LACROS combines the capabilities of Raman/depolarization lidar (Althausen et al., 2009), a MIRA-35 cloud radar (Bauer-Pfundstein and Görsdorf, 2007), a Doppler lidar (Bühl et al., 2012), a microwave radiometer, a sun-photometer and a disdrometer to measure height-resolved properties of aerosols and clouds. The Cloudnet framework (Illingworth et al., 2007) is used to derive microphysical parameters like liquid-water content (Pospichal et al., 2012) or ice-water content (Hogan et al., 2006). The following two cases have been selected to illustrate this variety and to serve as examples to be compared to model results.

\subsection{Case 1: warm mixed-phase cloud}

One of the warmest mixed-phase clouds within the data set was observed on 17 September 2011 between 00:00 and 00:22 UTC (see Fig. 1). The liquid part of the cloud extends from about 4250 to $4450 \mathrm{~m}$ height at temperatures of about $-6^{\circ} \mathrm{C}$ according to the GDAS (Global Data Assimilation System) reanalysis data for Leipzig. Liquid water content (LWC) is between 0.1 to $1 \mathrm{~g} \mathrm{~m}^{-3}$, whereas ice water content (IWC) is about 3-4 orders of magnitude smaller and reaches its maximum value within the virgae (see Fig. 2). Liquid water path (LWP) measured by a microwave radiometer varies between 20 and $50 \mathrm{~g} \mathrm{~m}^{-2}$ (mostly about $25 \mathrm{~g} \mathrm{~m}^{-2}$ ), whereas ice water path (IWP) is only slightly above the detection limit of about $0.01 \mathrm{~g} \mathrm{~m}^{-2}$ implying a rather large uncertainty with correspondingly large error bars. Virgae (falling ice) are observed down to about $3000 \mathrm{~m}$, which is close to the $0^{\circ} \mathrm{C}$ level. This is supported by Fig. 3 where the cloud radar (right panel) mainly shows particles falling from the top layer. Therefore, particles are mainly moving downwards (green color) and can be identified as ice particles by their size. Only at the very top (at about $4300 \mathrm{~m}$ ) are particles small enough to still be lifted upwards (yellow colors). The Doppler lidar (left panel), however, shows the motion of small cloud droplets at the predominantly liquid cloud top. Hence, in this plot the cloud-top turbulence becomes visible. Vertical wind speeds range from about -1.5 to $1.0 \mathrm{~m} \mathrm{~s}^{-1}$ with probability density function (pdf) maxima at -0.5 and $0.5 \mathrm{~m} \mathrm{~s}^{-1}$, respectively (Fig. 3).

\subsection{Case 2: colder mixed-phase cloud}

A much colder case was observed on 2 August 2012 between 21:00 and 21:40 UTC (see Fig. 4). Liquid water was measured around $7500 \mathrm{~m}$ at about $-25^{\circ} \mathrm{C}$ with a LWP between 10 and $30 \mathrm{~g} \mathrm{~m}^{-2}$ and a LWC of up to $0.1 \mathrm{~g} \mathrm{~m}^{-3}$ that is much smaller than case 1 . As can be expected due to the lower temperature, the ice phase was much more massive than in case 1 and reached down to about $5500 \mathrm{~m}$ with an IWP of about 1$10 \mathrm{~g} \mathrm{~m}^{-2}$ and an IWC of up to $0.01 \mathrm{~g} \mathrm{~m}^{-3}$, which means that in some parts of the cloud, ice and liquid water reach the 

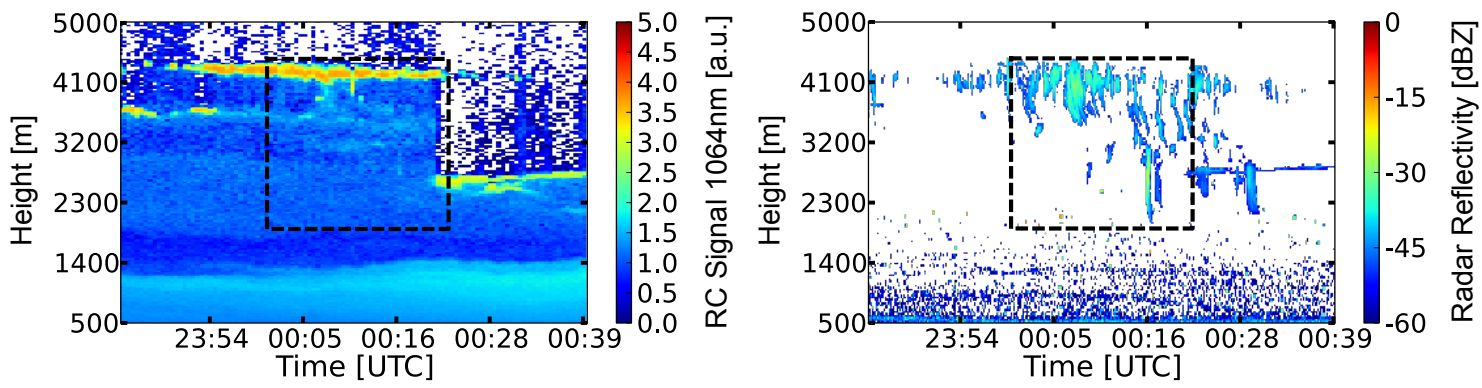

Figure 1. Lidar and radar observations on 17 September 2011 (case 1). Left: lidar range-corrected 1064 nm signal (in logarithmic scale, arbitrary units a. u.); right: radar reflectivity. The dashed box denotes the region for which case 1 observations are shown in the following figures.
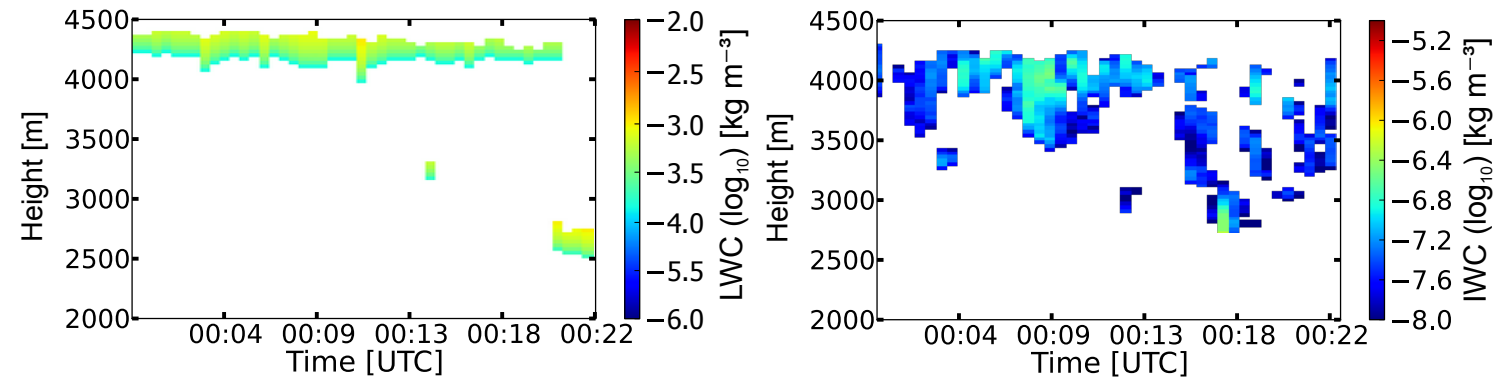

Figure 2. Cloudnet derived water contents for case 1. Left: liquid water content; right: ice water content (both in logarithmic scale).

same order of magnitude (see Fig. 5). Vertical wind speeds were in the same range as in the warmer case described above (Fig. 6).

Accuracy of the IWC is $\pm 50 \%$. For the LWC calculated by the scaled adiabatic approach, the same order of magnitude applies. Vertical wind speeds are measured directly by evaluation from the recorded cloud radar and Doppler lidar spectra. Errors are $\pm 0.15 \mathrm{~m} \mathrm{~s}^{-1}$ for the cloud radar and $\pm 0.05 \mathrm{~m} \mathrm{~s}^{-1}$ for the Doppler lidar. These errors are mainly due to the pointing accuracy of the two systems.

\section{Model description and initialization}

For the model studies, an Asai-Kasahara (AK) type model is used (Asai and Kasahara, 1967). The model geometry is axisymmetric and consists of an inner and an outer cylinder with radii of 100 and $1000 \mathrm{~m}$, respectively, resulting in a radius ratio of $1: 10$, which is typical for this setup. However, the geometric configuration of the model is not intended to match the geometry of the clouds (and the cloud-free spaces between the clouds) but is rather meant to provide the possibility of horizontal exchange between clouds and a cloudfree background.

The vertical resolution is constant with height and is chosen to be $\Delta z=25 \mathrm{~m}$ to give a sufficient resolution of the cloud layer and to roughly match the vertical resolution of the observations. In contrast to a parcel model, the vertically resolved model grid allows for a description of hydrometeor sedimentation. This is important especially for the fast growing ice crystals to realistically describe their interaction with the vapor and liquid phase (Wegener-Bergeron-Findeisen process). A time step of $1 \mathrm{~s}$ was used for the dynamics as well as for the microphysics.

However, in contrast to other Asai-Kasahara model studies, updrafts are not initialized by a heat and/or humidity pulse in certain layers for a given period of time. Instead, vertical velocity (updrafts and downdrafts) in the inner cylinder is prescribed, which is more similar to a kinematic model like the Kinematic Driver model (KiD) (Shipway and Hill, 2012). In that way dynamics can be controlled to make sure that it is close to the observations.

The cloud microphysics is described by the mixed-phase spectral microphysics module SPECS (Simmel and Wurzler, 2006; Diehl et al., 2006). SPECS provides a joint spectrum for the liquid phase (soluble wetted aerosol particles as well as cloud and rain drops) and one spectrum for the ice phase.

For this case study, collision processes between ice particles and drops (riming) and between ice particles and ice particles (accretion) are not taken into account. On the one hand, this is to exclude further uncertainties that would be introduced by the collision/collection kernel for those interactions; on the other hand, only small or neglectable effects are expected. Clouds are shallow which means that there is not much time for the ice particles to interact with droplets (especially when the ice is preferentially formed near cloud 

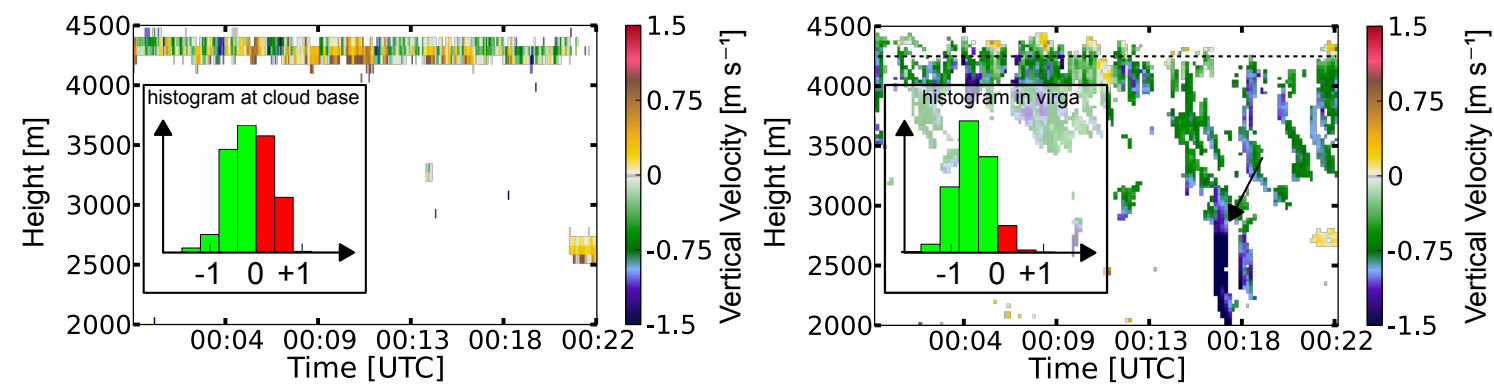

Figure 3. Vertical velocity for case 1. Left: derived from lidar (valid for more numerous smaller droplets at cloud base); right: derived from radar observations (valid for large particles; virgae).
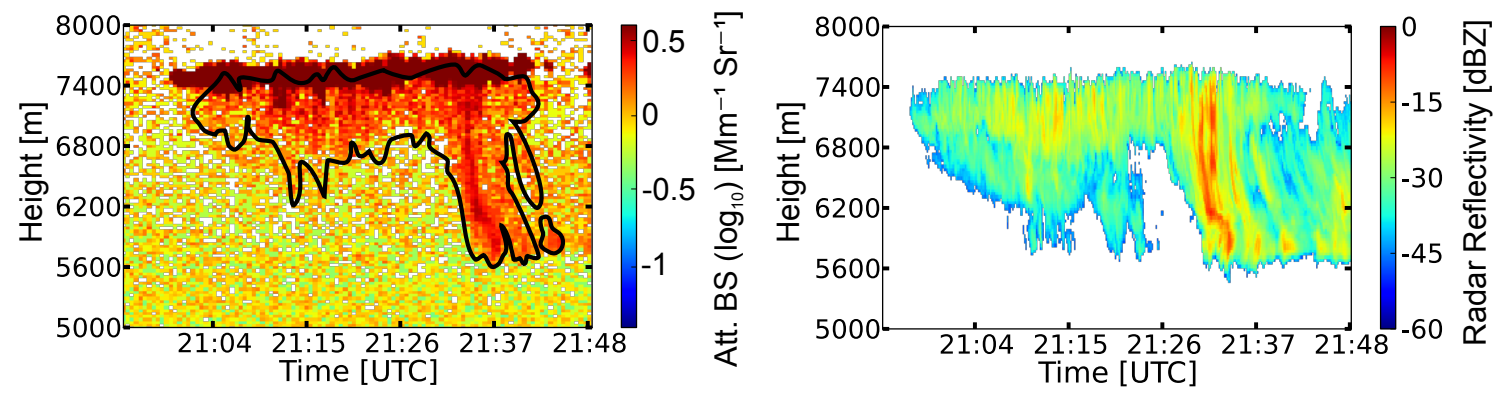

Figure 4. Lidar and radar observations on 2 August 2012 (case 2). Left: 532 nm attenuated backscatter coefficient; right: radar reflectivity.

base and sediments out soon). In addition, for case 1 ice particle concentrations are low, which highly limits the probability of collisions. At the low temperatures of case 2 sticking efficiency is expected to be low. This assumption is corroborated by the findings of Smith et al. (2009) stating that water vapor deposition (and sublimation), balanced by sedimentation are more important than accretional growth.

\subsection{Description of ice microphysics}

In the following, the differences in the description of the microphysics compared to Diehl et al. (2006) are described.

\subsubsection{Immersion freezing}

For this study, immersion freezing is assumed to be the only primary ice formation process. Since during the abovementioned observations no in situ measurements of the INPs are available, the parameterization of DeMott et al. (2010) is used assuming that all INPs are active in the immersion freezing mode. The parameterization of DeMott et al. (2010) is based on an empirical relation of INPs and the number of aerosol particles with radii $>250 \mathrm{~nm}\left(N_{\mathrm{AP}, r>250 \mathrm{~nm}}\right)$. To cover case 1 , the parameterization is extrapolated to $-5^{\circ} \mathrm{C}$ despite the fact that the underlying measurements were only taken at $-9{ }^{\circ} \mathrm{C}$ and below. As base case $N_{\mathrm{AP}, r>250 \mathrm{~nm}}=$ $10^{5} \mathrm{~kg}^{-1}$ air is used as input data for the parameterization resulting in about 0.01 active INPs per liter for $-6{ }^{\circ} \mathrm{C}$ (case 1 ) and about $0.5 \mathrm{INPs}$ per liter for $-25^{\circ} \mathrm{C}$ (case 2) at standard conditions. This corresponds to a relatively low number of larger aerosol particles but is well within the range observed by DeMott et al. (2010).

For the potential INPs a prognostic temperature resolved field with 20 temperature bins with a resolution of $1 \mathrm{~K}$ is introduced into SPECS. It ranges from -5 to $-25^{\circ} \mathrm{C}$ to cover the temperature range for the selected cases and can easily be changed for other case studies. This is a simplified version of the method used by Fridlind et al. (2007). The potential INP field is initially defined in every grid cell (layer) and is transported vertically with the given up-/downdrafts and horizontally exchanged between inner and outer cylinder in the same way as the other hydrometeor fields (drops and ice crystals). Immersion freezing occurs as soon as liquid drops above a certain size limit are present and the temperature of a certain potential INP bin is reached. Then the respective amount of drops freezes (if available) instantaneously and is transferred from the liquid to the frozen spectrum. If more drops larger than the size threshold of $10 \mu \mathrm{m}$ than active INPs are present, the INPs are distributed evenly over all drop size bins above the threshold value. The drop size threshold was chosen to restrict freezing to droplets and to prevent (large) non-activated aerosol particles at high relative humidity (but subsaturated with respect to water) outside the cloud from freezing. If ice crystals melt below the freezing level, they contribute to the potential INP field at that level. 

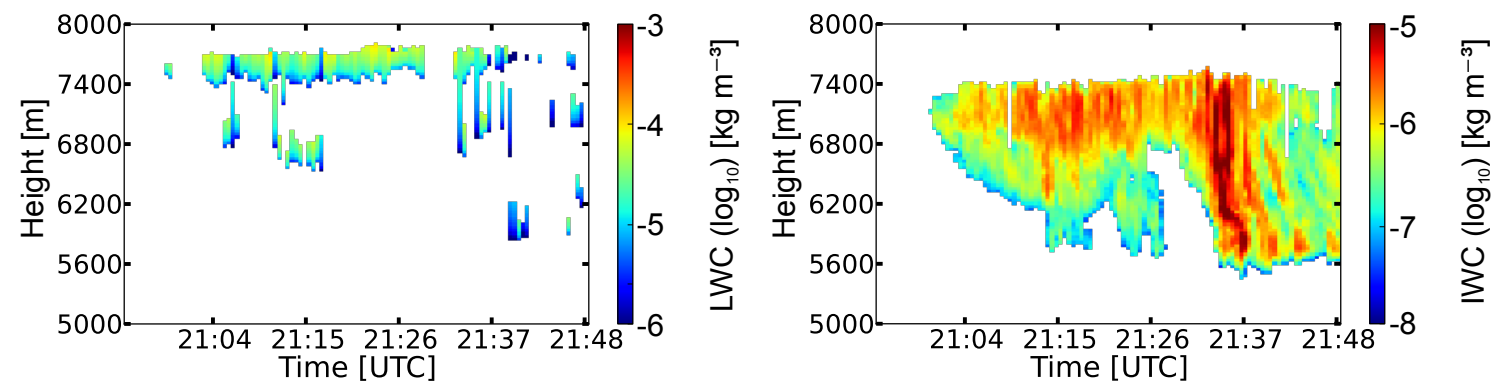

Figure 5. Cloudnet derived water contents for case 2. Left: liquid water content; right: ice water content (both in logarithmic scale).
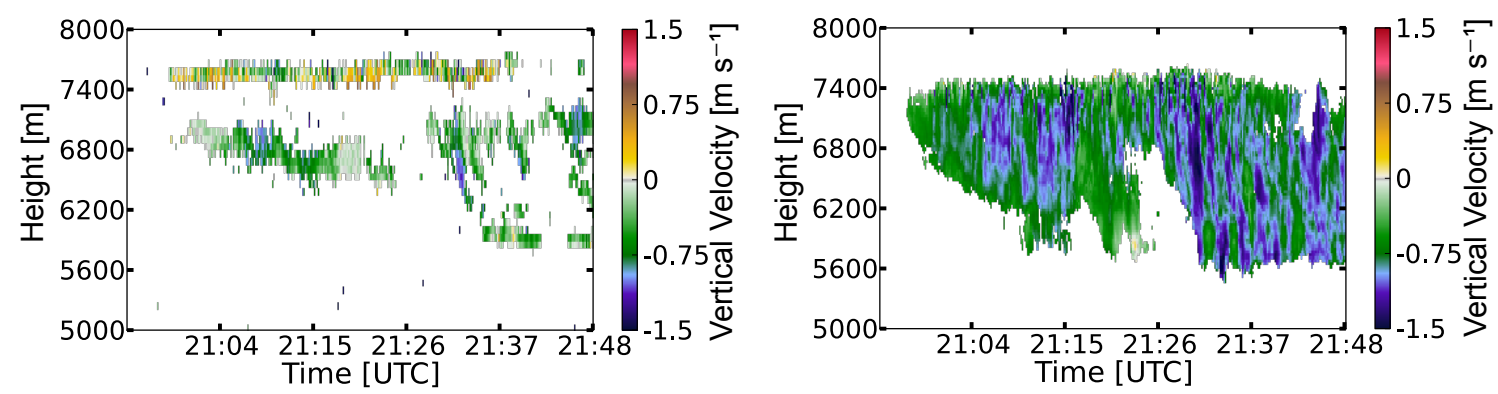

Figure 6. Vertical velocity for case 2. Left: derived from lidar (valid for more numerous smaller droplets at cloud base); right: derived from radar observations (valid for large particles; virgae).

\subsubsection{Ice particle shape}

It is well known that ice particle shape highly influences water vapor deposition (described by changing the capacitance of the particle) as well as terminal fall velocity of the ice particle. Therefore, instead of the previously chosen spherical ice particle shape, ice particles now can be prescribed as hexagonal columns or plates. The aspect ratio can be either constant for all size bins or be changed with size following the approach of Mitchell (1996). Typically, with increasing particle size, the deviation from an uniform aspect ratio increases. In our simulations, a constant uniform aspect ratio $(a r=1)$ is used as base case. From Mitchell (1996) the sizevarying aspect ratios for plates (ranging from 15 to $3000 \mu \mathrm{m}$ with a single description) and columns (for size ranges of 30 to $100 \mu \mathrm{m}, 100$ to $300 \mu \mathrm{m}$, and above $300 \mu \mathrm{m}$ in diameter) are calculated from the mass-dimension power laws and used for sensitivity studies.

The (relative) capacitance needed for the calculation of deposition growth of the ice crystals is modeled using the method of Westbrook et al. (2008) for the aspect ratios given above. Ice crystal terminal fall velocities are calculated according to Heymsfield and Westbrook (2010) using the same aspect ratios.

\subsection{Model initialization}

\subsubsection{Thermodynamics}

The Asai-Kasahara model has to be initialized with vertical profiles of temperature and dew point temperature either from reanalysis data (here GDAS) or radiosonde (RS) profiles from nearby stations (here Meiningen, Thuringia). Figure 7 shows profiles of temperature and relative humidities with respect to liquid water and to ice, respectively, for both cases. For case 1, profiles from both methods show a similar general behavior but the radiosonde profile of Meiningen measured at 00:00 UTC is used since it provides a finer vertical resolution than the GDAS reanalysis data (cp. Fig. 7). However, for case 2 the Meiningen RS profile misses the humidity layer at the level where the clouds were observed. This means that the profile is not representative for the given meteorological situation. Therefore, GDAS reanalysis data for Leipzig at 21:00 UTC were chosen. Finally, both profiles used show a sufficiently humid layer where the clouds were observed, so that the lifting of these layers leads to supersaturation and subsequent cloud formation.

As mentioned above, vertical velocity (updrafts and downdrafts) in the inner cylinder is prescribed at cloud level ranging from $h_{\text {bot }}$ to $h_{\text {top. }}$. The center of this interval is given by $h_{\text {mid }}=\left(h_{\text {top }}+h_{\text {bot }}\right) / 2$ and its half-depth by $h_{\text {depth }}=\left(h_{\text {top }}-\right.$ $\left.h_{\text {bot }}\right) / 2$. $h_{\text {bot }}$ ranges from 3800 to $4100 \mathrm{~m}$ for case 1 and from 7000 to $7300 \mathrm{~m}$ for case 2 . The respective values for $h_{\text {top }}$ are 4500 and $7700 \mathrm{~m}$. The vertical dependency (cf. Fig. 8, left) is 


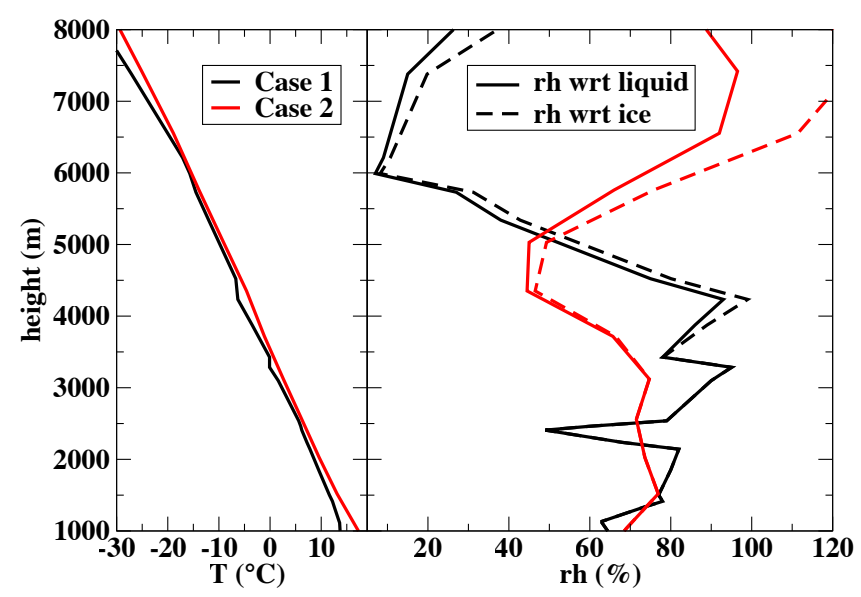

Figure 7. Vertical profiles of temperature (left) and relative humidity (right) with respect to liquid water (full lines) and ice (dashed lines) based on a radiosonde observation (Meiningen) for case 1 (black) and from GDAS (grid point Leipzig) for case 2 (red).

given by

$f_{h}(h)=\frac{h_{\text {depth }}^{2}-\left(h-h_{\text {mid }}\right)^{2}}{h_{\text {depth }}^{2}}$ forh $_{\text {bot }} \leq \mathrm{h} \leq \mathrm{h}_{\text {top }}$

resulting in the time- and height-dependent function

$w(h, t)=w_{\text {mid }}(t) f_{h}(h)$ forh $_{\text {bot }} \leq \mathrm{h} \leq \mathrm{h}_{\mathrm{top}}$

and $w(h, t)=0$ otherwise, defining $w_{\text {mid }}(t)$ as the updraft velocity at $h_{\text {mid }}$. In order to match the observed wind field distributions rather closely, $w_{\text {mid }}(t)$ is chosen as a stochastic function

$w_{\text {mid }}(t)=w_{\text {ave }}+f_{\text {scal }} \frac{\delta(t)^{3}}{|\delta(t)|}$,

where $w_{\text {ave }}$ is the average (large-scale) updraft velocity at $h_{\text {mid }}$ varying between $0.1 \mathrm{~m} \mathrm{~s}^{-1}$ and $0.4 \mathrm{~m} \mathrm{~s}^{-1}, f_{\text {scal }}$ is the scaling factor determining the range of updraft velocities (chosen as $4 \mathrm{~m} \mathrm{~s}^{-1}$ to obtain a difference of minimum and maximum velocity of $2 \mathrm{~m} \mathrm{~s}^{-1}$ ), and $\delta(t)$ is a random number ranging from -0.5 to +0.5 obtained from a linear stochastic process provided by FORTRAN. After $30 \mathrm{~s}$ model time, a new $\delta(t)$ is created. Different realizations of the stochastic process are tested (see below). For example, $w_{\text {mid }}(t)$ ranges from $-0.7 \mathrm{~m} \mathrm{~s}^{-1}$ to $1.3 \mathrm{~m} \mathrm{~s}^{-1}$ if $w_{\text {ave }}=0.3 \mathrm{~m} \mathrm{~s}^{-1}$ and $f_{\text {scal }}=4 \mathrm{~m} \mathrm{~s}^{-1}$ as it is shown in the temporal evolution and the histogram in Fig. 8.

Due to the height dependent vertical velocity $w$, a horizontal transport velocity $u_{k}$ (exchange between inner and outer cylinder) is induced in the Asai-Kasahara formulation for a given model layer $k$.

$u_{k}=-\frac{w_{k+\frac{1}{2}} \rho_{k+\frac{1}{2}}-w_{k-\frac{1}{2}} \rho_{k-\frac{1}{2}}}{f_{r} \Delta z \rho_{k}}$
Full indices $k$ indicate values at level centers whereas half indices $\left(k+\frac{1}{2}, k+\frac{1}{2}\right)$ describe values at level interfaces. $f_{r}=$ $2 / r_{i}$ is a geometry parameter with the radius $r_{i}=100 \mathrm{~m}$ of the inner cylinder.

The prescribed velocity field leads to the following effects (all descriptions are related to the inner cylinder if not stated otherwise explicitly):

- In the updraft phase: in the upper part (between $h_{\text {mid }}$ and $h_{\text {top }}$ ) of the updraft, mixing occurs from the inner to the outer cylinder, whereas in the lower part (between $h_{\text {low }}$ and $h_{\text {mid }}$ ) horizontal transport is from the outer cylinder into the inner one.

- For downdrafts it is the other way: this means that below $h_{\text {mid }}$ drops and ice particles are transported from the inner cylinder to the outer one and are therefore removed from the inner cylinder.

- below $h_{\text {low }}$ or above $h_{\text {top }}$, no horizontal exchange takes place.

The question arises to which extent this dynamical behavior reflects the real features of the observed clouds and whether this is critical for the topics aimed at in this study.

Prescribing vertical velocity in any way also means that a feedback of microphysics on dynamics due to phase changes (e.g., release of latent heat for condensing water vapor or freezing/melting processes) is not considered by the model.

\subsubsection{Aerosol distribution}

Since no in situ aerosol measurements are available, literature data are used. The Raman lidar observations do not show any polluted layers for both cases; therefore, data from LACE98 (Petzold et al., 2002) are used which should be representative for the free troposphere over Leipzig. For case 1 values for the lower free troposphere (M6), for case 2 those from the upper free troposphere (M1), are used (see Petzold et al., 2002, Table 6).

\section{Model results: dynamics}

In a first step, the aim is to achieve a sufficient agreement concerning macroscopic cloud features, as well as (liquid phase) microphysics, as far as they were observed. The following parameters describing model dynamics (updraft velocity) are varied to identify a "best case", which in the second step can be used to perform sensitivity studies with respect to (ice) microphysics (see also Tables 1 and 2).

- $h_{\text {low }}$ : ranging from 3800 to $4100 \mathrm{~m}$ for the warmer and from 7000 to $7300 \mathrm{~m}$ for the colder case, this parameter influences the vertical cloud extent and, therefore, liquid water content and liquid water path. 

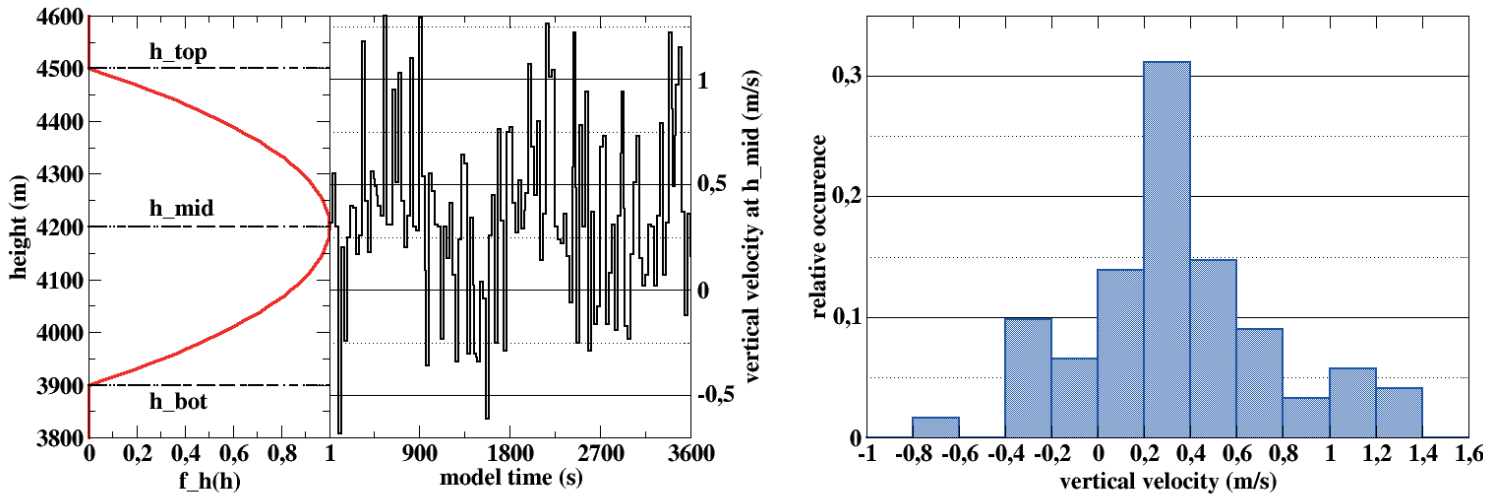

Figure 8. Vertical velocity field of the inner cylinder for case 1. Left: height dependence (red line) and temporal evolution of one realization of the stochastic vertical velocity field (black line) for $w_{\text {ave }}=0.3 \mathrm{~m} \mathrm{~s}^{-1}$ at $h_{\text {mid }}$. Right: histogram of velocity field. Vertical velocity for case 2 is identical but for heights between 7100 and $7700 \mathrm{~m}$.

- $w_{\text {ave }}$ : ranging from 0.1 to $0.4 \mathrm{~m} \mathrm{~s}^{-1}$. Higher average updraft also leads to higher LWC. Due to the lateral mixing processes the model setup requires a positive updraft velocity in average to form and maintain clouds.

- $\delta$ : four different realizations of the stochastic process are used. This influences the timing of the cloud occurrence as well as LWC and LWP but not systematically.

All model results shown refer to the inner cylinder.

\subsection{Case 1: warm mixed-phase cloud}

Figures 9 and 11 show time-height plots of the liquid- (contours, linear scale) and ice-water (colors, logarithmic scale) content for case 1 illustrating the cloud sensitivity with respect to variation of cloud base $\left(h_{\text {bot }}\right)$, average vertical up$\operatorname{draft}\left(w_{\text {ave }}\right)$, and the realization of the stochastic process. Liquid clouds form in the updraft regions (cp. Fig. 8), whereas in the downdrafts the liquid phase vanishes at least partly. If active INPs are available ice formation can take place within the liquid part of the cloud. The INPs are partly already active near liquid cloud base, which means that they trigger freezing as soon as the droplets are formed. Less efficient INPs become active after further cooling above cloud base. After ice formation rapid depositional growth takes place and the ice particles almost immediately start to sediment. Due to the supersaturation with respect to ice even below liquid cloud base, ice particles still grow while sedimenting, reaching their maximum size before, finally, subsaturated regions are reached and sublimation sets in. Figures 10 and 12 show the time evolution of liquid (lower panel) and ice water path (upper panel) for the same parameters varied, reflecting the same temporal patterns. Table 1 summarizes the maximum values for LWC/IWC, LWP/IWP as well as cloud droplet and ice particle number concentration (CDN/IPN) for all dynamics sensitivity runs for case 1 .

One can clearly observe, that a lower $h_{\text {bot }}$ (Fig. 9) results in a lower cloud base, larger vertical cloud extent as well as more liquid water. The LWC maxima are within a factor of 2 for varying $h_{\text {bot }}$. A similar trend is observed for the ice phase (see also Fig. 10), but IWC maxima differ only by about $25 \%$. However, the values of the two maxima of the condensed phase after about 15-20 min and about $40 \mathrm{~min}$ model time are quite different. The first maximum is more pronounced for the ice phase whereas the second one is larger for the liquid phase. While the liquid phase is dominated by the updraft velocity (see Fig. 8) the ice phase additionally depends on INP supply. In the first ice formation event at $15 \mathrm{~min}$, all INPs active at the current temperature actually form ice leading to an INP depletion. Due to the horizontal exchange with the outer cylinder the INP reservoir is refilled, but only to a certain extent when the second cloud event after $40 \mathrm{~min}$ sets in. Due to the limited INP supply, the second ice maximum is weaker than the first one. The stochastic velocity fluctuations cause fluctuations in relative humidity, which are directly reflected by the liquid phase parameters, whereas the ice phase generally reacts much slower. Sensitivity of CDN and IPN with respect to change of $h_{\text {bot }}$ does not seem to be systematic.

Increasing the average updraft velocity, $w_{\text {ave }}$ leads to a similar increase of liquid water and ice as lowering $h_{\text {bot }}$ (see Figs. 11, upper panel and 12, left). This can be expected since more water vapor flows through the cloud and is able to condense. However, a certain limit seems to be reached for W_w04, since the increase of LWP slows down (see maximum value at $40 \mathrm{~min}$ in Fig. 12, left). This is due to the enhanced horizontal exchanged following Eq. (4). Additionally, the stronger updrafts allow the ice particles to have a longer presence time in the vicinity of the cloud and, therefore, an enhanced growth at comparably high supersaturation with respect to ice before sedimentation sets in at larger sizes. This also leads to an accumulation of ice particles and, therefore, to a higher IPN. Surprisingly, CDN depends only weakly and not systematically on $w_{\text {ave }}$, which is in contrast to the typical enhancement of CDN with increasing updraft velocities. 
Table 1. Overview of the model results for the dynamic sensitivity runs for the warmer case 1 (maximum values of L/IWC: liquid/ice water content; L/IWP: liquid/ice water path; CDN: cloud drop number; IPN: ice particle number).

\begin{tabular}{llcrrrrr}
\hline Run & $\begin{array}{l}\text { Parameter value } \\
\text { differing from base case }\end{array}$ & $\begin{array}{r}\text { LWC } \\
\mathrm{g} \mathrm{m}^{-3}\end{array}$ & $\begin{array}{r}\text { IWC } \\
10^{-3} \mathrm{~g} \mathrm{~m}^{-3}\end{array}$ & $\begin{array}{r}\text { LWP } \\
\mathrm{g} \mathrm{m}^{-2}\end{array}$ & $\begin{array}{r}\text { IWP } \\
10^{-3} \mathrm{~g} \mathrm{~m}^{-2}\end{array}$ & $\begin{array}{l}\mathrm{CDN} \\
\mathrm{cm}^{-3}\end{array}$ & $\begin{array}{l}\text { IPN } \\
\mathrm{L}^{-1}\end{array}$ \\
\hline W_base & - & 0.355 & 0.379 & 41.33 & 62.27 & 46.89 & 0.0197 \\
\hline W_h38 & $h_{\text {bot }}=3800 \mathrm{~m}$ & 0.426 & 0.408 & 57.05 & 73.11 & 48.63 & 0.0235 \\
W_h40 & $h_{\text {bot }}=4000 \mathrm{~m}$ & 0.289 & 0.357 & 28.58 & 58.12 & 61.48 & 0.0240 \\
W_h41 & $h_{\text {bot }}=4100 \mathrm{~m}$ & 0.219 & 0.324 & 18.23 & 45.81 & 59.53 & 0.0208 \\
\hline W_w01 & wave $=0.1 \mathrm{~m} \mathrm{~s}^{-1}$ & 0.187 & 0.200 & 17.41 & 31.73 & 43.36 & 0.0138 \\
W_w02 & wave $=0.2 \mathrm{~m} \mathrm{~s}^{-1}$ & 0.297 & 0.300 & 32.86 & 47.18 & 54.57 & 0.0175 \\
W_w04 & wave $=0.4 \mathrm{~m} \mathrm{~s}^{-1}$ & 0.382 & 0.448 & 44.48 & 78.25 & 52.66 & 0.0219 \\
\hline W_r1 & stoch. realiz. r1 & 0.336 & 0.316 & 40.32 & 54.85 & 64.26 & 0.0163 \\
W_r3 & stoch. realiz. r3 & 0.381 & 0.314 & 42.88 & 54.48 & 43.03 & 0.0167 \\
W_r4 & stoch. realiz. r4 & 0.346 & 0.245 & 40.91 & 46.93 & 47.42 & 0.0151 \\
\hline
\end{tabular}

Table 2. Overview of the model results for the dynamic sensitivity runs for the colder case 2 (maximum values of L/IWC: liquid/ice water content; L/IWP: liquid/ice water path; CDN: cloud drop number; IPN: ice particle number).

\begin{tabular}{llrrrrrr}
\hline Run & $\begin{array}{l}\text { Parameter value } \\
\text { differing from base case }\end{array}$ & $\begin{array}{r}\text { LWC } \\
\mathrm{g} \mathrm{m}^{-3}\end{array}$ & $\begin{array}{r}\text { IWC } \\
\mathrm{g} \mathrm{m}^{-3}\end{array}$ & $\begin{array}{r}\text { LWP } \\
\mathrm{g} \mathrm{m}^{-2}\end{array}$ & $\begin{array}{r}\text { IWP } \\
\mathrm{g} \mathrm{m}^{-2}\end{array}$ & $\begin{array}{r}\text { CDN } \\
\mathrm{cm}^{-3}\end{array}$ & $\begin{array}{r}\text { IPN } \\
1^{-1}\end{array}$ \\
\hline C_base & - & 0.377 & 0.041 & 29.35 & 10.71 & 70.56 & 0.462 \\
\hline C_h70 & $h_{\text {bot }}=7000 \mathrm{~m}$ & 0.452 & 0.048 & 43.06 & 11.34 & 71.33 & 0.432 \\
C_h72 & $h_{\text {bot }}=7200 \mathrm{~m}$ & 0.296 & 0.035 & 18.71 & 10.11 & 90.51 & 0.396 \\
C_h73 & $h_{\text {bot }}=7300 \mathrm{~m}$ & 0.215 & 0.028 & 10.54 & 9.27 & 77.61 & 0.337 \\
\hline C_w01 & \multirow{2}{*}{$w_{\text {ave }}=0.1 \mathrm{~m} \mathrm{~s}^{-1}$} & 0.219 & 0.040 & 17.19 & 8.01 & 76.98 & 0.292 \\
C_w02 & $w_{\text {ave }}=0.2 \mathrm{~m} \mathrm{~s}^{-1}$ & 0.316 & 0.044 & 25.89 & 9.42 & 74.40 & 0.415 \\
C_w04 & $w_{\text {ave }}=0.4 \mathrm{~m} \mathrm{~s}^{-1}$ & 0.402 & 0.045 & 30.58 & 11.85 & 98.37 & 0.439 \\
\hline C_r1 & stoch. realiz. r1 & 0.366 & 0.023 & 29.37 & 6.57 & 86.64 & 0.257 \\
C_r3 & stoch. realiz. r3 & 0.399 & 0.046 & 30.22 & 9.95 & 79.65 & 0.341 \\
C_r4 & stoch. realiz. r4 & 0.373 & 0.049 & 29.53 & 8.33 & 95.89 & 0.419 \\
\hline
\end{tabular}

Figures 11 (lower panel) and 12 (right) show that different realizations of the stochastic process (as explained above in Sect. 3.2.1) lead to different temporal cloud evolutions. However, differences in maximum LWP and LWC are much smaller than those discussed above. Variations in maximum IWP and IWC, as well as CDN and IPN, are in the range of about $30 \%$. This is also true for average LWP ranging from $18 \mathrm{~g} \mathrm{~m}^{-2}$ for W_r1 to $26 \mathrm{~g} \mathrm{~m}^{-2}$ for W_r3. However, despite the different maxima and temporal evolutions of IWP, average IWP is almost identical for the different stochastic realizations $\left(0.023 \mathrm{~g} \mathrm{~m}^{-2}\right)$. This shows that changing the stochastic realization influences cloud evolution in detail (timing) but does not change the overall picture.

With maximum values between 17 and $57 \mathrm{~g} \mathrm{~m}^{-2}$, the modeled liquid water path is in the same range as the observed values (20-50 $\mathrm{g} \mathrm{m}^{-2}$ ), especially for the "wetter" runs (smaller $h_{\text {bot }}$, larger $w_{\text {ave }}$ ). Average LWP typically is about half $(40-60 \%)$ of the maximum value for most of the runs, which also fits well into the observations. Ice forms within the liquid layer and sediments to about $3800 \mathrm{~m}$ for most runs, which is less than for the observations. The (maximum) modeled ice mixing ratio is in the same order of magnitude as the observed one (about $10^{-7} \mathrm{~kg} \mathrm{~m}^{-3}$ ). The same holds for the ice water path with values of about $0.01 \mathrm{~g} \mathrm{~m}^{-2}$ for both, model and observation. For the other values, no observational data are available for comparison.

\subsection{Case 2: colder mixed-phase cloud}

Due to the lower temperatures of case 2 much more INPs are active and much more ice is produced than in case 1 (see Figs. 13-16 as well as Table 2). This also means that near the cloud base much more active INPs are available and that a further cooling within the clouds only slightly increases the number of active INPs leading again to a preferential ice nucleation near the liquid cloud base. Due to the lower temperatures and the more massive ice formation, the virgae reach 

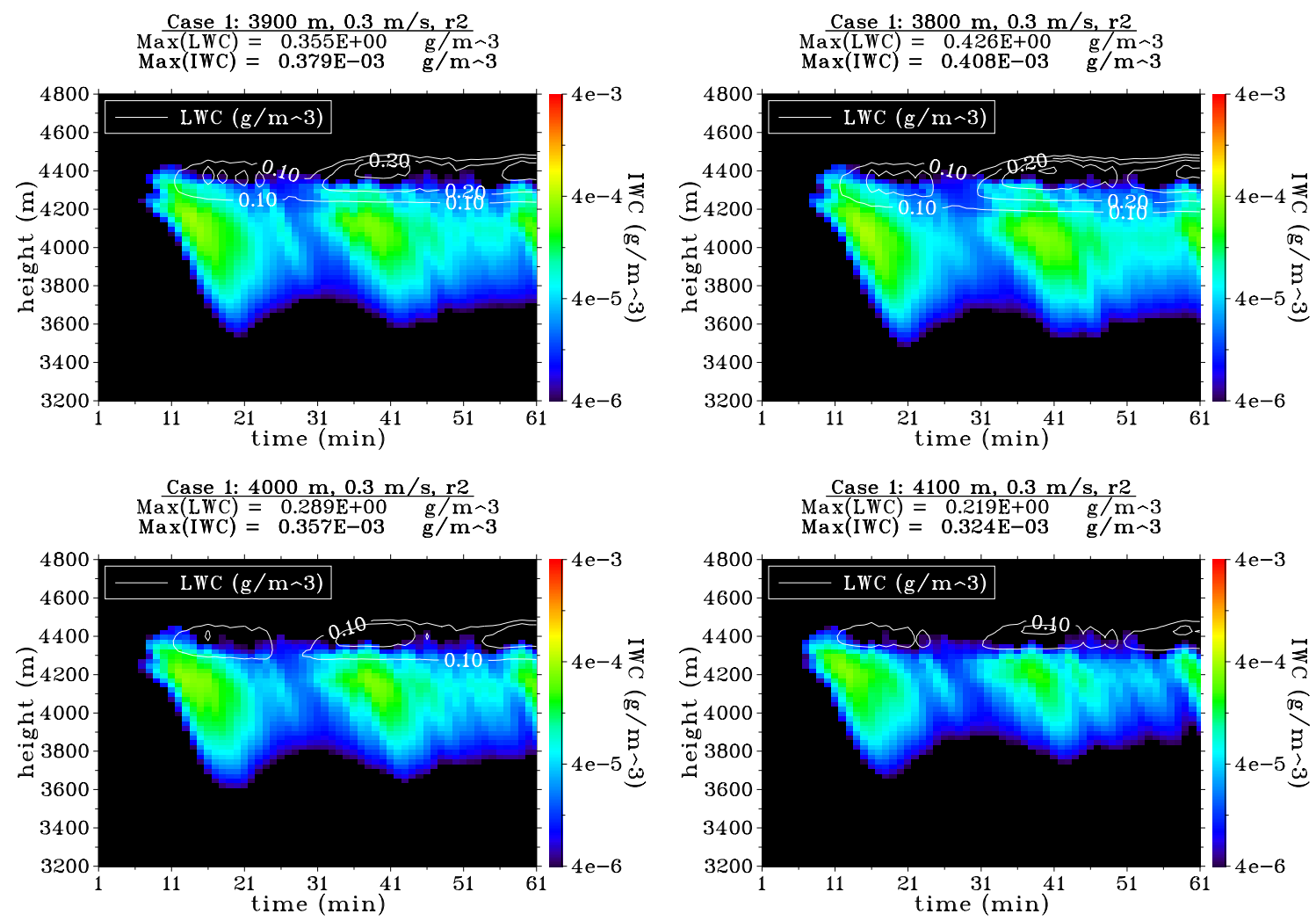

Figure 9. LWC (contours) and IWC (colors, logarithmic scale) for case 1. Comparison of different values for $h_{\text {bot }}$ (upper left: W_base, $h_{\text {bot }}=3900 \mathrm{~m}$; upper right: W_h38, $h_{\text {bot }}=3800 \mathrm{~m}$; lower left: W_h40, $h_{\text {bot }}=4000 \mathrm{~m}$; lower right: W_h41, $h_{\text {bot }}=4100 \mathrm{~m}$.)

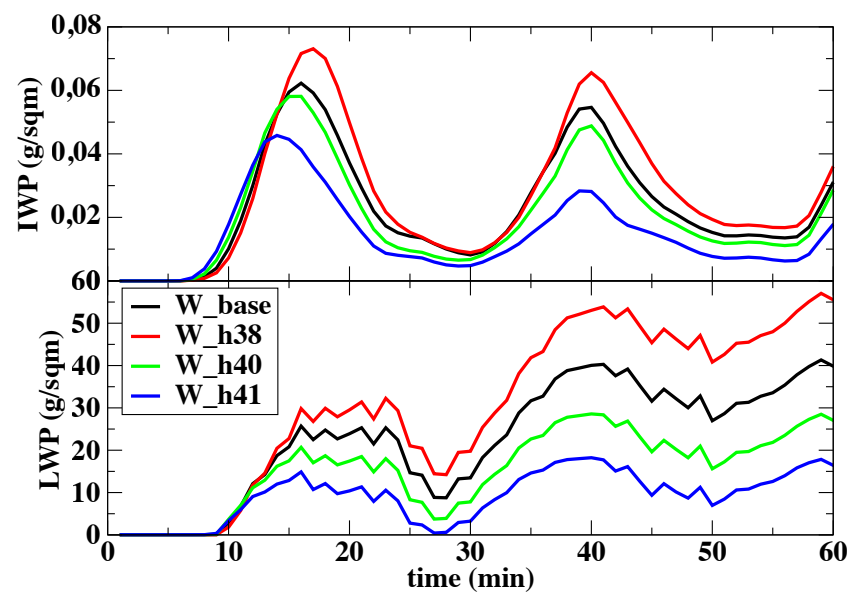

Figure 10. Liquid (lower panel) and ice water paths (upper panel) for case 1. Comparison of the different values for $h_{\text {bot }}$.

down to more than $1500 \mathrm{~m}$ below liquid cloud base, which is in concordance with the observations. The principal behavior with respect to the sensitivity parameters is similar to case 1: the liquid phase is enhanced by either decreasing $h_{\text {bot }}$ or increasing $w_{\text {ave }}$, showing the "saturation" effect slightly more pronounced as in case 1. Different stochastic realiza- tions only weakly influence the maximum and average values of the liquid phase but change the timing of occurrence. Generally, the variability of the ice phase is weaker than in case 1 . The different stochastic realizations show the highest variability in IWC and IWP. Different variations of $h_{\text {bot }}$ show almost identical IWPs, whereas changing $w_{\text {ave }}$ at least slightly influences maximum IWC and IWP, which again can be attributed to the ice particle accumulation in the updraft. Liquid water path is smaller than in case 1 and reaches maximum values between 10 and $43 \mathrm{~g} \mathrm{~m}^{-2}$, which well covers the observed maximum value of about $20 \mathrm{~g} \mathrm{~m}^{-2}$. Cloudnet observations show an IWC of $10^{-7}-10^{-5} \mathrm{~kg} \mathrm{~m}^{-3}$, which is an increase by a factor of 10-100 compared to case 1 . Similar values are obtained by the model results underlining the strong temperature dependency of the ice nucleation process.

\section{Sensitivity studies}

In the previous section it could be shown that dynamical parameters can be chosen in a way that the model results (in terms of LWP, IWP as well as cloud geometry) are in good agreement with the observations. This allows one to perform sensitivity studies with respect to cloud microphysics. To cover the proper sensitivities, we have to answer the 

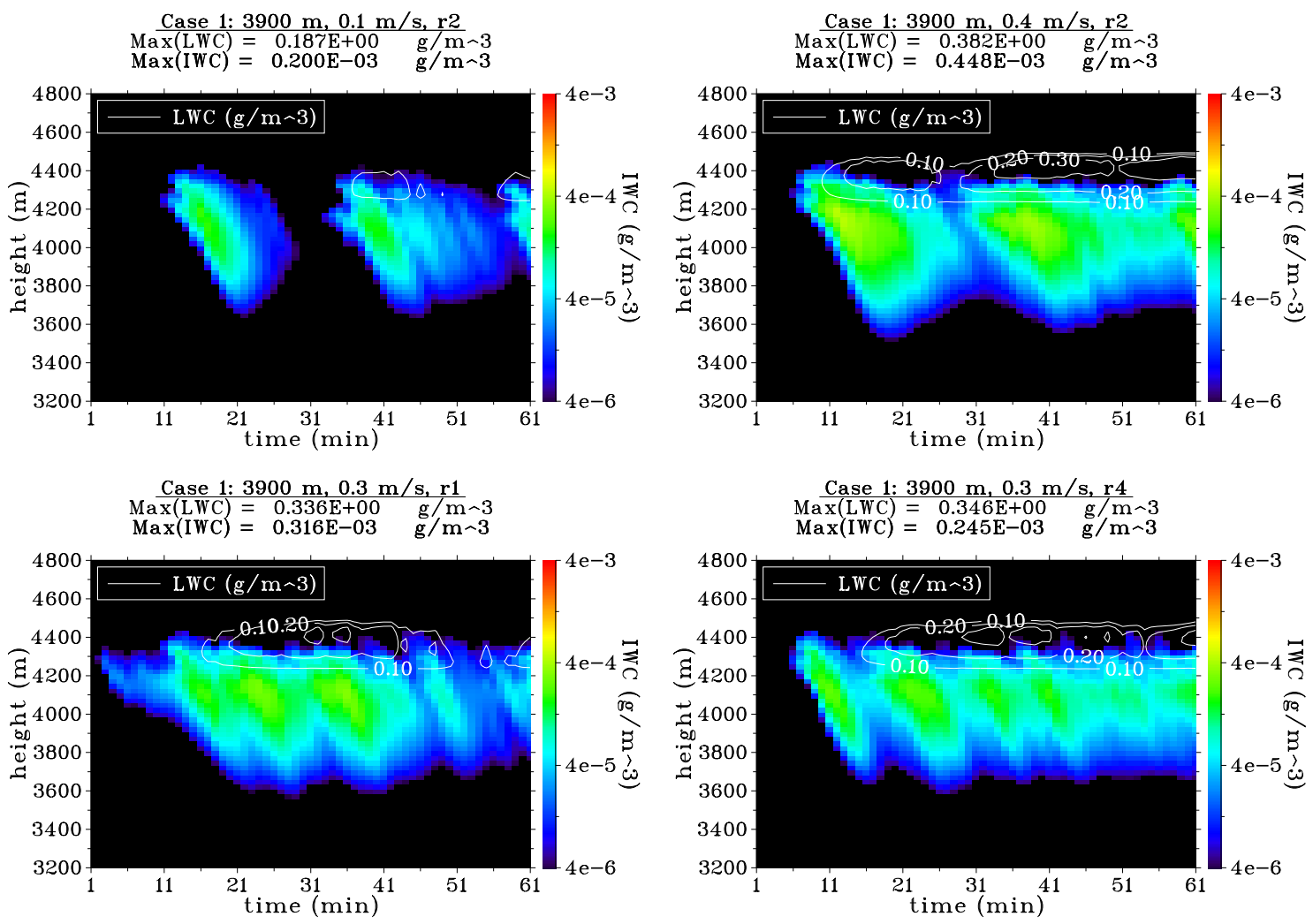

Figure 11. LWC (contours) and IWC (colors, logarithmic scale) for case 1 . Comparison of different average updraft velocities $w_{\text {ave }}$ (upper panel: left: $\mathrm{W} \_\mathrm{w} 01, w_{\mathrm{ave}}=0.1 \mathrm{~m} \mathrm{~s}^{-1}$; right: $\mathrm{W} \_\mathrm{w} 04, w_{\mathrm{ave}}=0.4 \mathrm{~m} \mathrm{~s}^{-1}$ ) and different stochastic realizations (lower: left: W_r1, r1; right: W_r4, r4).
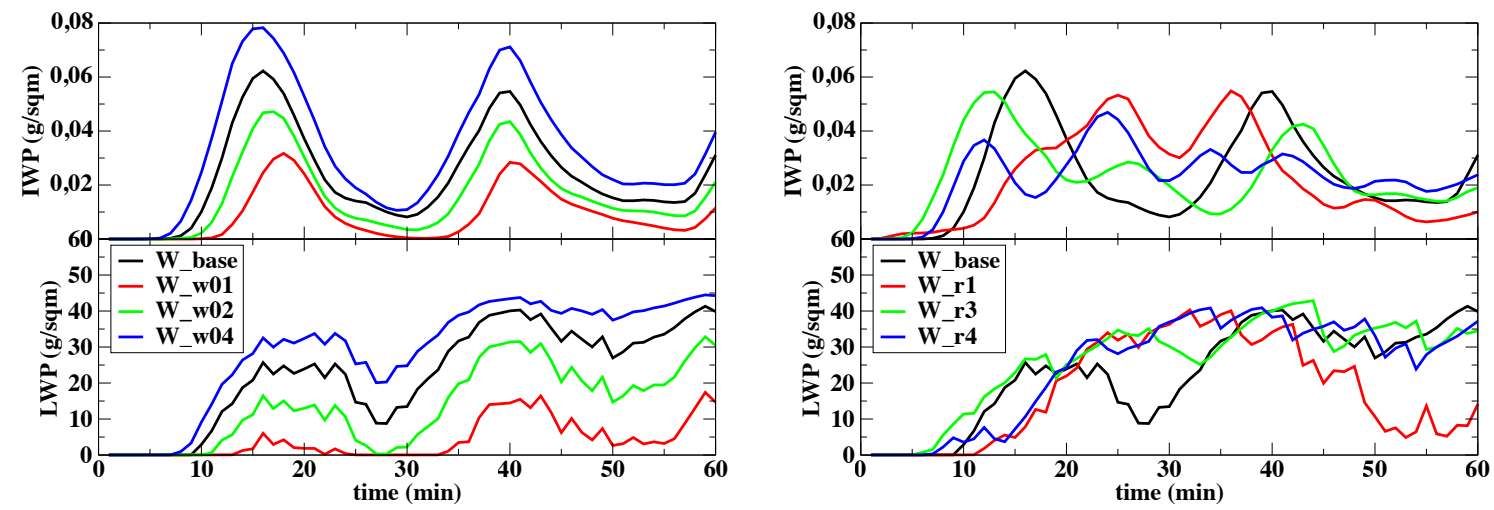

Figure 12. Liquid (lower panels) and ice water paths (upper panels) for case 1. Comparison of the different values for $w_{\text {ave }}$ (left) and the different stochastic realizations (right).

question of which microphysical parameters are expected to have a large influence on mixed phase microphysics and are rather uncertain to be estimated. This leads to a (temperaturedependent) INP number $\left(N_{\text {INP }}\right)$ that directly influences the ice particle number but mostly is poorly known. To be consistent with the freezing parameterization of the model, $N_{\text {INP }}$ is varied by changing $N_{\mathrm{AP}}, r>250 \mathrm{~nm}$, which additionally is easier to observe in most cases. A second parameter is the shape of the ice particles that does not influence the primary freezing process but the subsequent growth by water vapor deposition onto existing ice particles and, therefore, the total ice mass produced. Their relative importance shall be quantified and also be compared to the influence of dynamics discussed above. 

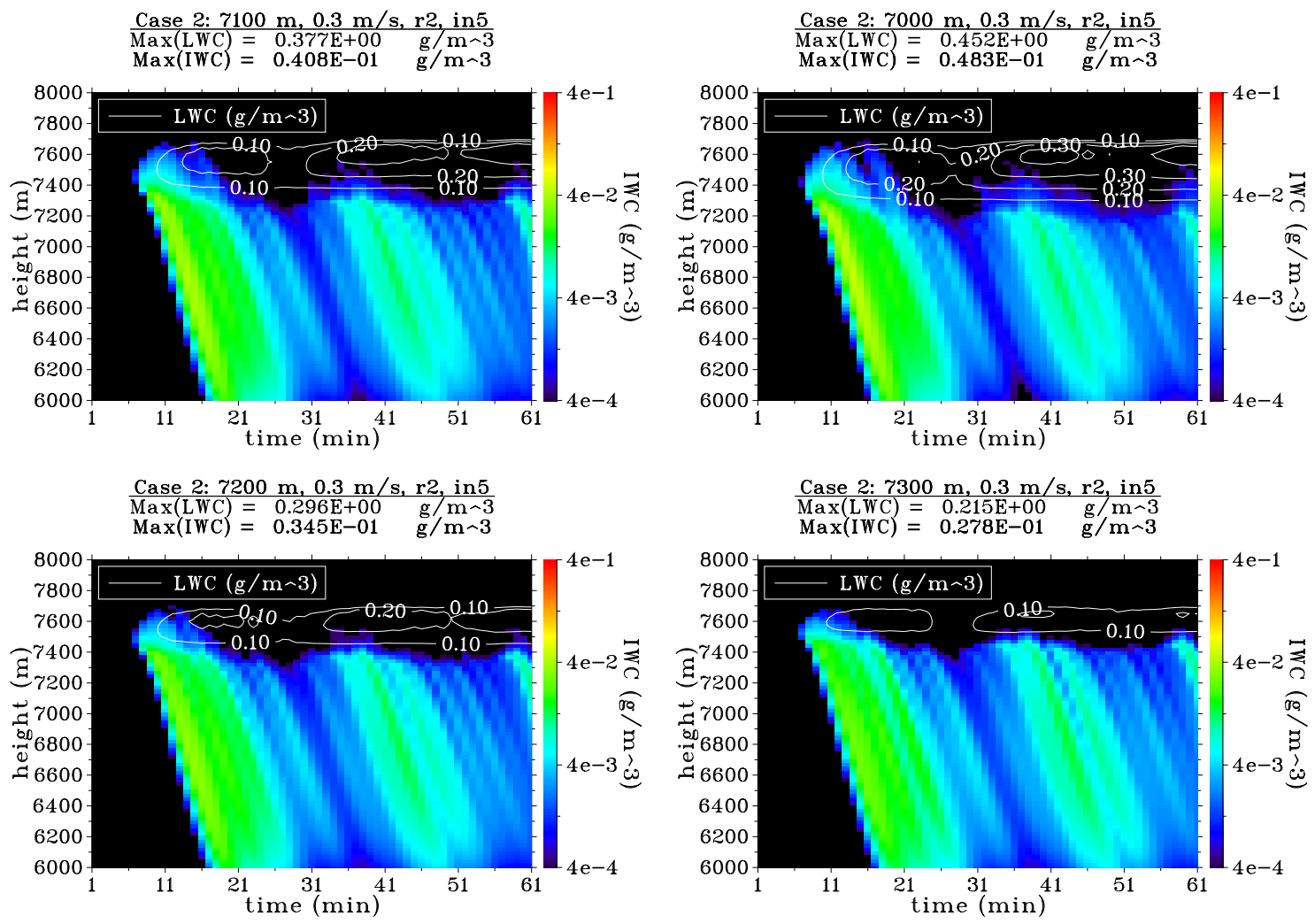

Figure 13. LWC (contours) and IWC (colors, logarithmic scale) for case 2. Comparison of different values for $h_{\text {bot }}$ (upper left: C_base, $h_{\text {bot }}=7100 \mathrm{~m}$; upper right: C_h70, $h_{\text {bot }}=7000 \mathrm{~m}$; lower left: C_h72, $h_{\text {bot }}=7200 \mathrm{~m}$; lower right: C_h73, $\left.h_{\text {bot }}=7300 \mathrm{~m}\right)$.

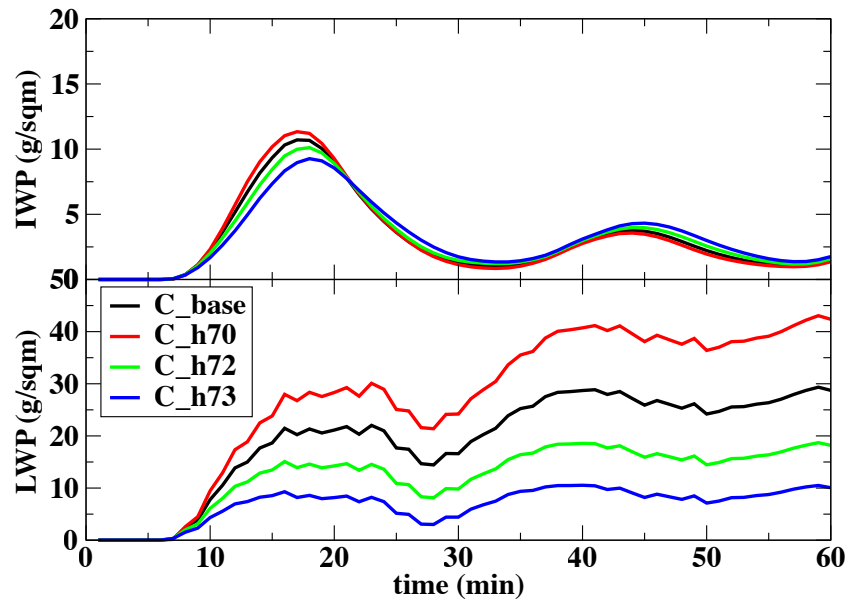

Figure 14. Liquid (lower panel) and ice water paths (upper panel) for case 2. Comparison of the different values for $h_{\mathrm{bot}}$.

\subsection{INP number}

Changing $N_{\mathrm{AP}}, r>250 \mathrm{~nm}$ leads to a temperature-dependent change of INP number, which is relatively small for warmer conditions. However, the effect increases with decreasing temperature. This is illustrated by the following numbers.
The parameterization of DeMott et al. (2010) gives about 0.009 active INPs per liter at standard conditions $\left(N_{\mathrm{INP}}\right)$ when $N_{\mathrm{AP}, r>250 \mathrm{~nm}}=10^{5} \mathrm{~kg}^{-1}$ at $T=-5^{\circ} \mathrm{C}$. A tenfold increase to $\mathrm{N}_{\mathrm{AP}}, r>250 \mathrm{~nm}=10^{6} \mathrm{~kg}^{-1}$ results in about $0.012 \mathrm{ac}$ tive INPs per liter, which is a rise of only about $35 \%$. For $T=-7^{\circ} \mathrm{C}$, INP number rises by about $65 \%$ for a tenfold increase of $N_{\mathrm{AP}, r}>250 \mathrm{~nm}$. This shows that for those rather high temperatures considered for case 1 , a massive change in $N_{\mathrm{AP}, r}>250 \mathrm{~nm}$ leads to relatively small changes in $N_{\text {INP }}$ and only a small effect on the ice phase can be expected. This is confirmed by Fig. 17 (left) showing liquid and ice water contents for W_in6. IWC is enhanced by less than $60 \%$ for W_in6 and by about $160 \%$ for W_in7, which is consistent for the given temperature range (see Table 3). Similar values are obtained for the change in IPN. This directly leads to the conclusion that the individual ice particles grow independently from each other. Their individual growth history is (in contrast to drop growth) only influenced by thermodynamics as long as their number is low enough, which seems to be the case here.

This is confirmed by Fig. 18 showing drop and ice particle size distributions at the time when the maximum IWP is reached (16 $\mathrm{min}$ for case $1,17 \mathrm{~min}$ for case 2 ). For case 1 (upper panel), the liquid phase (contours) is unaffected by the INP enhancement. Despite the increase of ice particle 

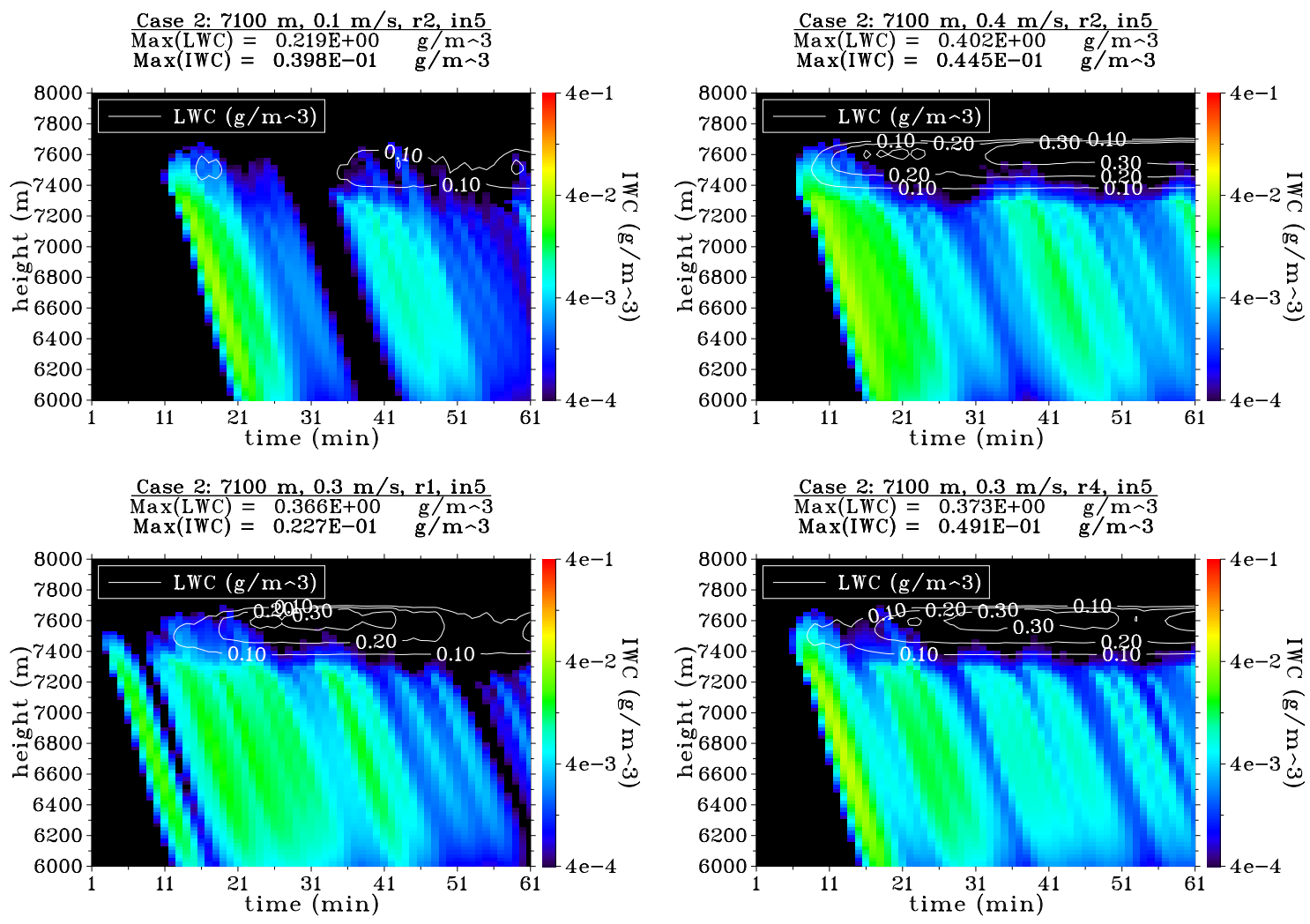

Figure 15. LWC (contours) and IWC (colors, logarithmic scale) for case 2. Comparison of different average updraft velocities $w_{\text {ave }}$ (upper left: C_w01, $w_{\text {ave }}=0.1 \mathrm{~m} \mathrm{~s}^{-1}$, right: C_w04, $w_{\text {ave }}=0.4 \mathrm{~m} \mathrm{~s}^{-1}$ ) and the different stochastic realizations (lower left: C_r1, r1, right: C_r4, r4).

Table 3. Overview of the model results for the microphysical sensitivity runs for the warmer case 1 (maximum values of L/IWC: liquid/ice water content, L/IWP: liquid/ice water path, CDN: cloud drop number, IPN: ice particle number).

\begin{tabular}{llcrrrrr}
\hline Run & $\begin{array}{l}\text { Parameter value } \\
\text { differing from base case }\end{array}$ & $\begin{array}{r}\text { LWC } \\
\mathrm{g} \mathrm{m}^{-3}\end{array}$ & $\begin{array}{r}\text { IWC } \\
10^{-3} \mathrm{~g} \mathrm{~m}^{-3}\end{array}$ & $\begin{array}{r}\text { LWP } \\
\mathrm{g} \mathrm{m}^{-2}\end{array}$ & $\begin{array}{r}\text { IWP } \\
\mathrm{g} \mathrm{m}^{-2}\end{array}$ & $\begin{array}{r}\text { CDN } \\
\mathrm{cm}^{-3}\end{array}$ & $\begin{array}{l}\text { IPN } \\
1^{-1}\end{array}$ \\
\hline W_in6 & $N_{\mathrm{AP}, r>250 \mathrm{~nm}=10^{6} \mathrm{~kg}^{-1}}$ & 0.354 & 0.619 & 41.31 & 0.10 & 46.69 & 0.0296 \\
W_in7 & $N_{\mathrm{AP}, r>250 \mathrm{~nm}=10^{7} \mathrm{~kg}^{-1}}$ & 0.354 & 1.000 & 41.24 & 0.17 & 41.61 & 0.0450 \\
\hline W_col & ice shape: columns & 0.353 & 1.830 & 41.20 & 0.27 & 42.90 & 0.0257 \\
W_pla & ice shape: plates & 0.353 & 2.850 & 41.13 & 0.45 & 43.41 & 0.0267 \\
\hline
\end{tabular}

number and mass, the shape of the ice particle size distribution (colors) is not changed. The smallest ice particles can be observed at three discrete height (and temperature) levels caused by the temperature resolved parameterization of the potential INPs described in Sect. 3.1.1. In reality this part of the spectrum showing rather freshly nucleated and fast growing ice particles should be continuous over the height range from about 4100 to $4400 \mathrm{~m}$. Nevertheless, the total number of ice particles formed is described correctly.

One can conclude that increasing INP number therefore increases ice particle number as well as ice mass proportionally. Generally, the ice mass remains small and the liquid phase is not affected by the ice mass increase. Those results are supported by Fig. 19 (left) showing an unchanged LWP and a proportionally growing IWP for increased INP numbers.

For the colder case 2 the parameters are varied in the same way. However, one big difference is that a tenfold increase of $N_{\text {AP, } r>250 \mathrm{~nm}}$ at $T=-25^{\circ} \mathrm{C}$ results in a much larger change in active INPs. Their number rises by $300 \%$ from about 0.5 per liter to about 2 per liter following the parameterization. This is reflected by the IPN values in Table 4. Figure 17 (right) and Table 4 show that ice mass increases in such a way that liquid water is depleted partially (C_in6 by about $50 \%$ ) or almost totally (C_in7) due to the WegenerBergeron-Findeisen process. Compared to $\mathrm{C}_{-}$base, ice is en- 

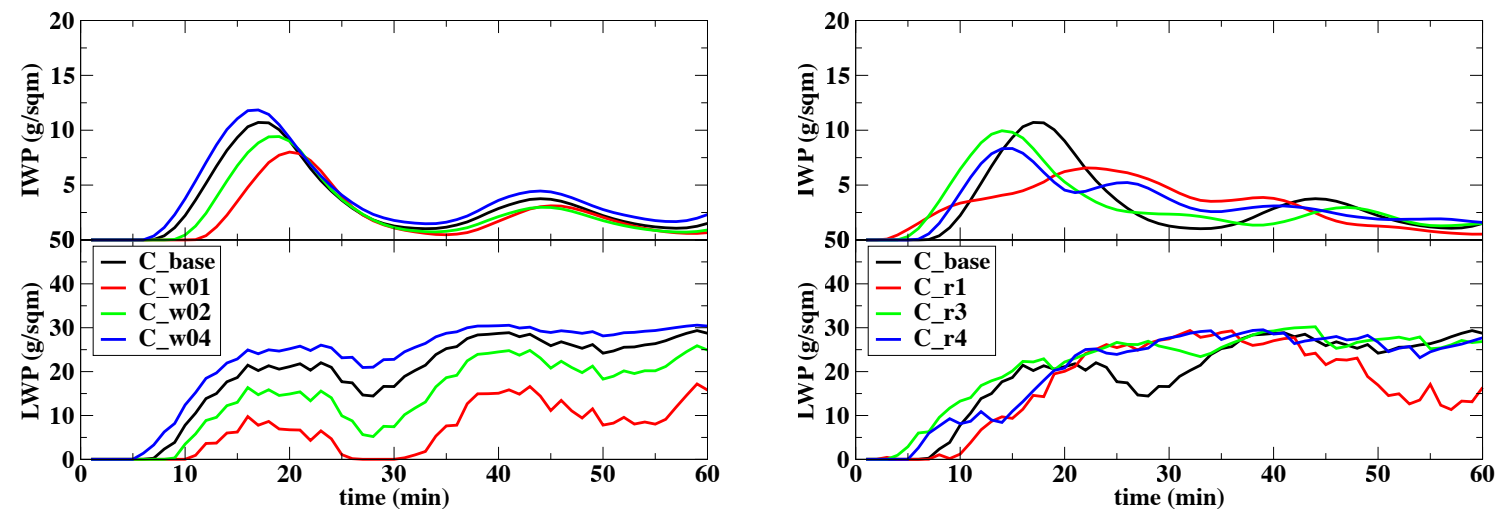

Figure 16. Liquid (lower panels) and ice water paths (upper panels) for case 2. Comparison of the different values for $w_{\text {ave }}$ (left) and the different stochastic realizations (right).
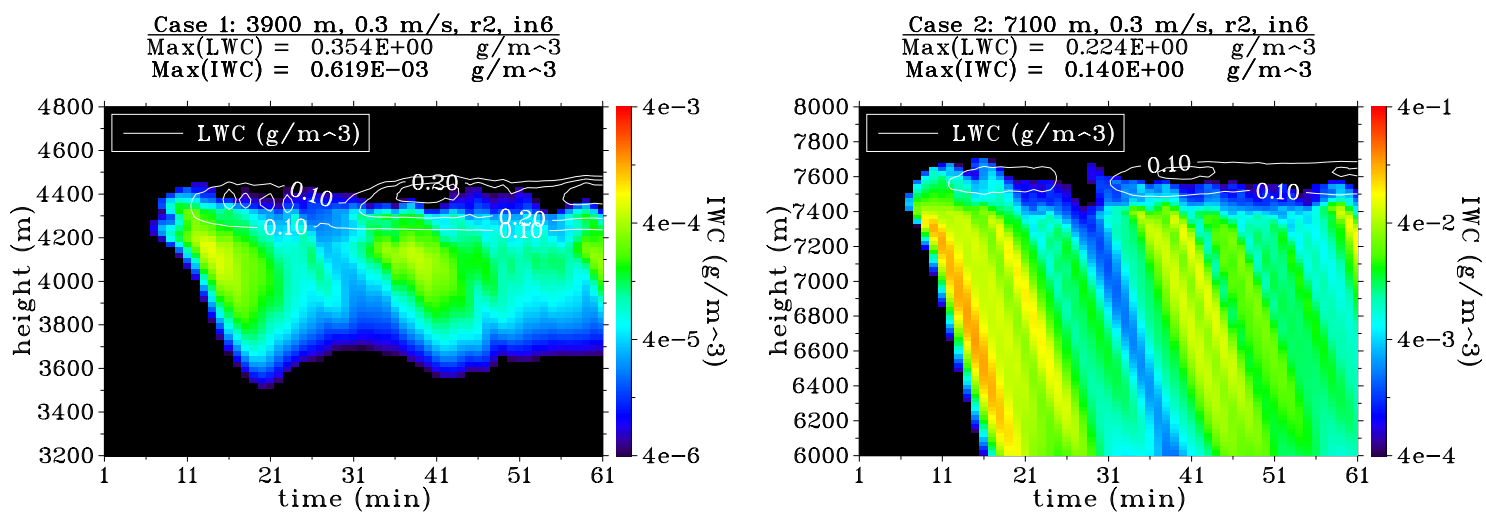

Figure 17. LWC (colors) and IWC (contours, logarithmic scale) for case 1 (W_in6, left) and case 2 (C_in6, right). Enhancing IN by increasing $N_{\mathrm{AP}, r}>250 \mathrm{~nm}$ by a factor of 10 .

hanced by a factor of 3-4 for C_in6 and about 10 for C_in7 whereas IPN increases by a factor of 12 . This can also be seen in the IWP (Fig. 19, right, red lines) showing a limited increase for $\mathrm{C}_{-}$in7, especially for the first maximum after $17 \mathrm{~min}$. This means that the results for C_in6 are still consistent with an independent growth of the individual ice particles (as described above) despite the relatively high ice occurrence.

This is verified by the size distributions in Fig. 18 (lower panel). As in case 1 the ice particle size distributions only differ by the number/mass, but not by shape. Additionally, the decrease in the liquid phase is reflected also in the drop spectrum showing a more shallow liquid part of cloud as well as droplet distribution shifted to smaller sizes.

However, for C_in7 the ice particles compete for water vapor, which becomes clear from (i) the depletion of liquid water (resulting in a lower supersaturation with respect to ice) and (ii) the ice mass enhancement factor being below the value expected from the ice nucleation parameterization and below that of IPN. This means that despite the higher number of INPs and, therefore, ice particles, the amount of ice is limited by the thermodynamic conditions that result in the production of more but smaller ice particles, similar to the Twomey effect for drop activation.

As mentioned earlier, ice particle growth is not only restricted to the liquid part of the cloud but also occurs in the layer below liquid cloud base, which is still supersaturated with respect to ice. This leads to a decrease in relative humidity in this part of the cloud, which in turn weakens or suppresses droplet formation by shifting liquid cloud base to higher altitudes. The lower LWC for the runs with higher IWC therefore cannot only be attributed to the WBF processes but also to this indirect effect.

\subsection{Ice particle shape}

As discussed previously, for most of the cases (except for C_in7) changing the parameters in the section above does neither influence the ice particles themselves nor their individual growth. Additionally, due to their low number, there is almost no competition between the ice particles for water vapor, and, therefore, ice water content scales linearly with ice particle number. In contrast to this, changing the ice 

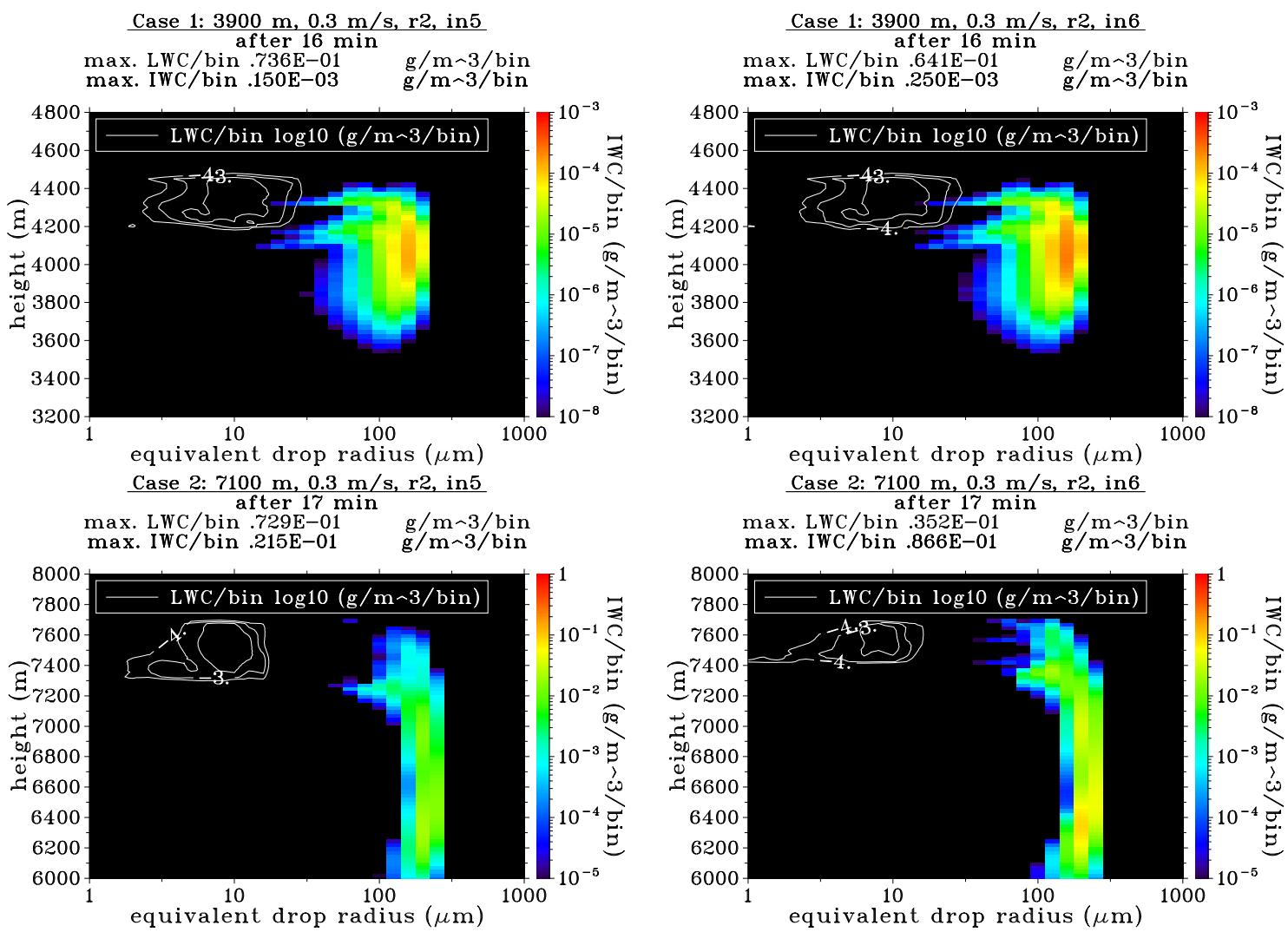

Figure 18. LWC (contours) and IWC per bin (colors, both logarithmic scale) for case 1 (upper panel) and case 2 (lower panel) for the respective base case (left) and the case with enhanced IN number (right; in6) after 16 and 17 minutes model time, respectively, corresponding to the IWP maximum of the base case runs.

Table 4. Overview of the model results for the microphysical sensitivity runs for the colder case 2 (maximum values of L/IWC: liquid/ice water content; L/IWP: liquid/ice water path; CDN: cloud drop number; IPN: ice particle number).

\begin{tabular}{llrrrrrr}
\hline Run & $\begin{array}{l}\text { Parameter value } \\
\text { differing from base case }\end{array}$ & $\begin{array}{r}\text { LWC } \\
\mathrm{g} \mathrm{m}^{-3}\end{array}$ & $\begin{array}{r}\text { IWC } \\
\mathrm{g} \mathrm{m}^{-3}\end{array}$ & $\begin{array}{r}\text { LWP } \\
\mathrm{g} \mathrm{m}^{-2}\end{array}$ & $\begin{array}{r}\text { IWP } \\
\mathrm{g} \mathrm{m}^{-2}\end{array}$ & $\begin{array}{r}\text { CDN } \\
\mathrm{cm}^{-3}\end{array}$ & $\begin{array}{r}\text { IPN } \\
1^{-1}\end{array}$ \\
\hline C_in6 & $N_{\mathrm{AP}, r} r 250 \mathrm{~nm}=10^{6} \mathrm{~kg}^{-1}$ & 0.224 & 0.140 & 13.09 & 34.75 & 80.29 & 1.380 \\
C_in7 & $N_{\mathrm{AP}, r}>250 \mathrm{~nm}=10^{7} \mathrm{~kg}^{-1}$ & 0.036 & 0.446 & 2.58 & 57.98 & 46.67 & 5.208 \\
\hline C_col & ice shape: columns & 0.237 & 0.223 & 14.33 & 46.78 & 78.40 & 0.462 \\
C_col_in4 & ice shape: columns, $N_{\mathrm{AP}, r}>250 \mathrm{~nm}=10^{4} \mathrm{~kg}^{-1}$ & 0.378 & 0.076 & 30.01 & 14.93 & 74.75 & 0.139 \\
C_pla & ice shape: plates & 0.182 & 0.294 & 9.94 & 57.11 & 39.41 & 0.472 \\
C_pla_in4 & ice shape: plates, $N_{\mathrm{AP}, r} r 250 \mathrm{~nm}=10^{4} \mathrm{~kg}^{-1}$ & 0.362 & 0.102 & 27.80 & 19.21 & 74.44 & 0.129 \\
\hline
\end{tabular}

particle shape from quasi-spherical $(a r=1)$ to columns or plates with size-dependent axis ratios deviating from unity results in an increase of water vapor deposition on the individual ice particles leading to enhanced ice water content due to larger individual particles when ice particle numbers remain unchanged. This is due to (i) enhanced relative capacitance resulting in faster water vapor deposition and (ii) lower terminal velocities of the ice particles leading to longer residence times in vicinity of conditions with supersaturation with respect to ice.
Figure 20 (left) shows the results for the runs using hexagonal columns (W_col) as prescribed ice particle type. Compared to the previous results (W_base, W_in6, W_in7) more ice mass is produced (see Table 3 ) but still the liquid part of the cloud remains unaffected (compare also LWP and IWP in Fig. 19, left). Similar results are obtained for the assumption of plate-like ice particles (W_pla). The mass increase results from the larger ice particle size due to the reasons discussed above, which can be seen from Fig. 21 showing the size distributions for W_col at different times. On the 

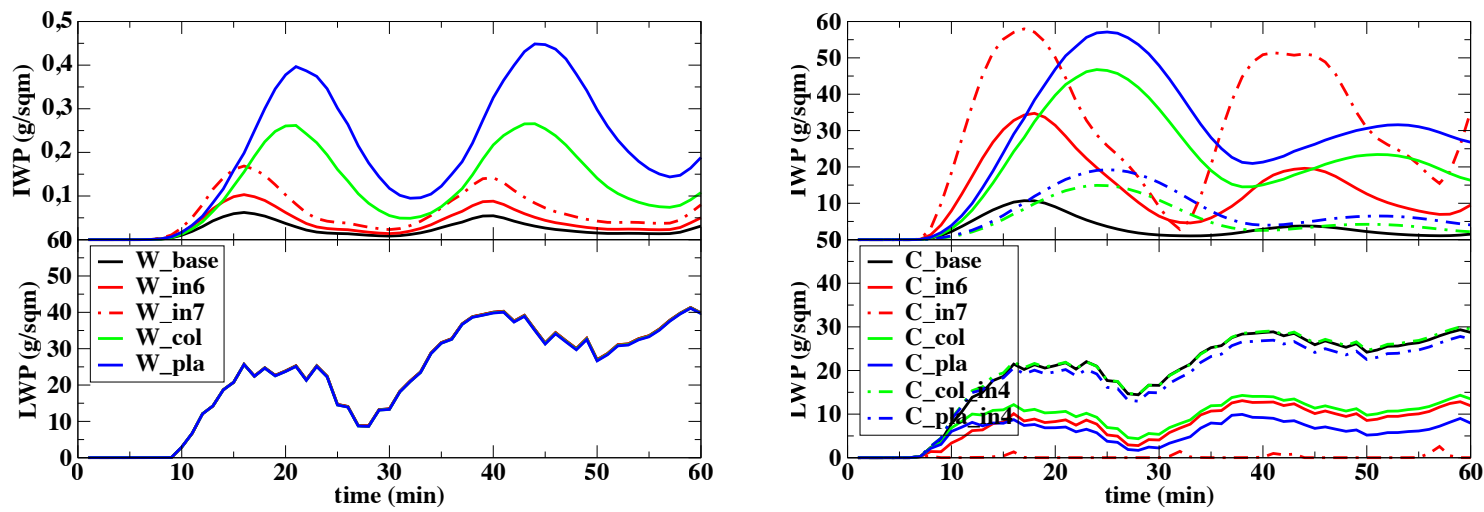

Figure 19. Liquid (lower panel) and ice water paths (upper panel) for case 1 (left) and case 2 (right). Comparison of the sensitivities with respect to IN number and ice particle shape.

upper left panel W_col is shown after 16 min corresponding to Fig. 18. Compared to W_base, larger ice particles are produced leading to more ice mass (equivalent radius up to $300 \mu \mathrm{m}$ compared to $189-238 \mu \mathrm{m}$ for the base case). Additionally, due to the lower fall speed of the columns $\left(1.03 \mathrm{~m} \mathrm{~s}^{-1}\right.$ vs. $\left.1.75-2.24 \mathrm{~m} \mathrm{~s}^{-1}\right)$, the maximum of the ice is at about $4200 \mathrm{~m}$ compared to $4100 \mathrm{~m}$ for the base case. On the upper right panel, size distributions after $21 \mathrm{~min}$ are shown corresponding to the IWP maximum of W_col. Ice particles have grown larger (equivalent radius up to $378 \mu \mathrm{m}$, length of the columns increases from about 3 to $4.5 \mathrm{~mm}$ ) and sedimentation has developed further with increasing terminal velocity $\left(1.13 \mathrm{~m} \mathrm{~s}^{-1}\right)$. Similar results are obtained for plates (W_pla) with terminal velocities of $0.89-1.21 \mathrm{~m} \mathrm{~s}^{-1}$, equivalent radii of 300-476 $\mu \mathrm{m}$, and maximum dimension of 1.8 $3.2 \mathrm{~mm}$.

The lower terminal velocity of columns and plates despite their larger size is leading to the stronger tilting of the virgae. Additionally, the IPN is enhanced by about $30 \%$ although ice nucleation is identical to $\mathrm{W} \_$base. This can be attributed to the lower fall velocities, too, leading to an accumulation of ice particles. The differences between W_col and W_pla are caused by both, the higher relative capacitances of and lower terminal fall velocities of plates compared to columns (at least when their axis ratios are chosen following (Mitchell, 1996)).

For case 2 (C_col and C_pla), the liquid water reduction due to the Bergeron-Findeisen process is similar to $\mathrm{C}_{-}$in6 (see Fig. 20, right, and Table 4). In contrast to the respective case 1 runs, less ice is produced than for $C_{-}$in7. The tilting of the virgae is not as strong as in W_col, which is due to the larger ice particle sizes leading to higher terminal fall velocities (1.43-1.60 $\mathrm{m} \mathrm{s}^{-1}$ ). Additionally, the lower air density leads to an increase of terminal velocity of more than $10 \%$ independently from shape. Figure 21 (lower panel) shows the size distributions for $\mathrm{C}_{-}$col at different times. Due to the longer growth time larger individual ice particles than in case 1 are produced (equivalent radius up to $600 \mu \mathrm{m}$ compared to $300 \mu \mathrm{m}$ for the base case).

To decide whether independent ice particle growth or competition occurs, further runs with less INPs (C_col_in4 and C_pla_in4) are discussed (see Fig. 19, right). IWC and IWP of these runs (in4) are about one-third of the values of the respective runs with more INPs (in5). For ice particle number, a factor of slightly more than 3 occurs, which means that a weak competition for water vapor occurs for $\mathrm{C}_{-}$col and C_pla resulting in slightly smaller individual ice particles compared to C_col_in4 and C_pla_in4.

\section{Conclusions}

The model system AK-SPECS was applied to simulate dynamical and microphysical processes within altocumulus clouds. Sensitivity studies on relative contributions on cloud evolution as well as comparisons to observations were made.

Variation of the dynamic parameters as it was done in Sect. 4 leads to systematic differences mainly in the liquid phase (LWC, LWP), which can easily be explained. More liquid water is produced when either cloud base is lowered (corresponding to a larger vertical cloud extent) or vertical wind velocity is increased. However, the effects of the dynamics on the ice phase are surprisingly small, at least smaller than those on the liquid phase. Increasing vertical velocity leads to an accumulation of the smaller ice particles in the enhanced updraft.

On the other hand, much larger differences in terms of IWC and IWP were found when microphysical parameters like INP number or ice particle shape were varied under identical dynamic conditions. This is valid for both cases studied. However, at least for the ice nucleation parameterization used, sensitivity of INP number strongly increased with decreasing temperature.

This means that relatively large differences concerning the ice phase can only be reached when either INP number dif- 

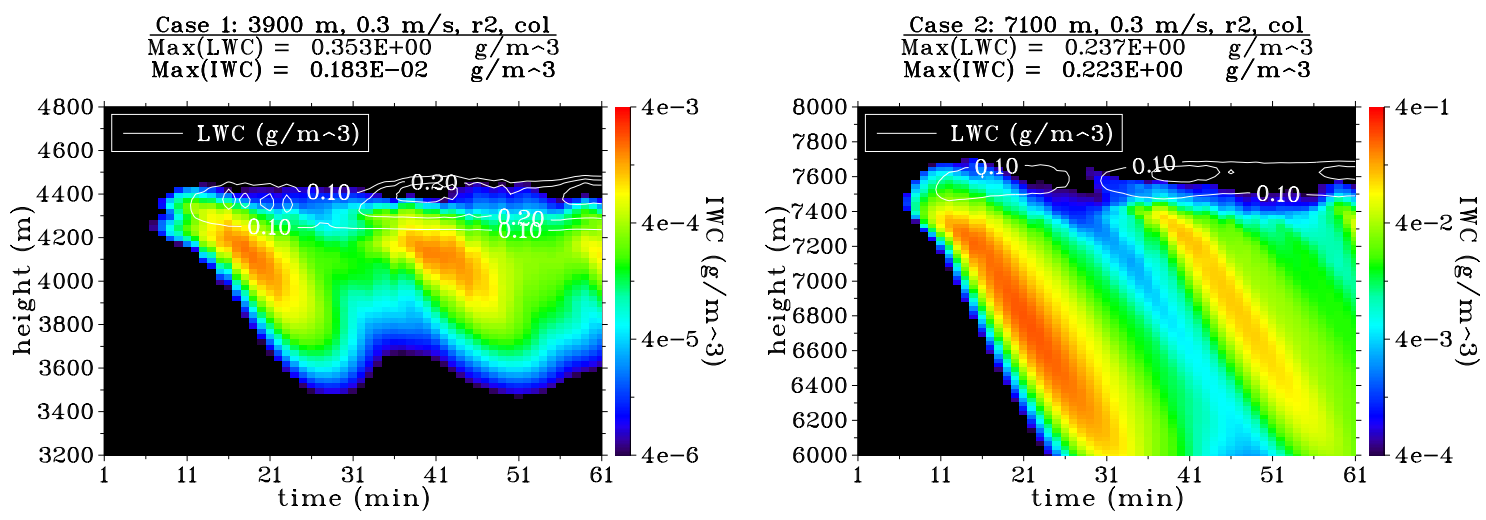

Figure 20. LWC (contours) and IWC (colors, logarithmic scale). Results for changing ice particle shape to hexagonal columns for case 1 (W_col, left) and case 2 (C_col, right).
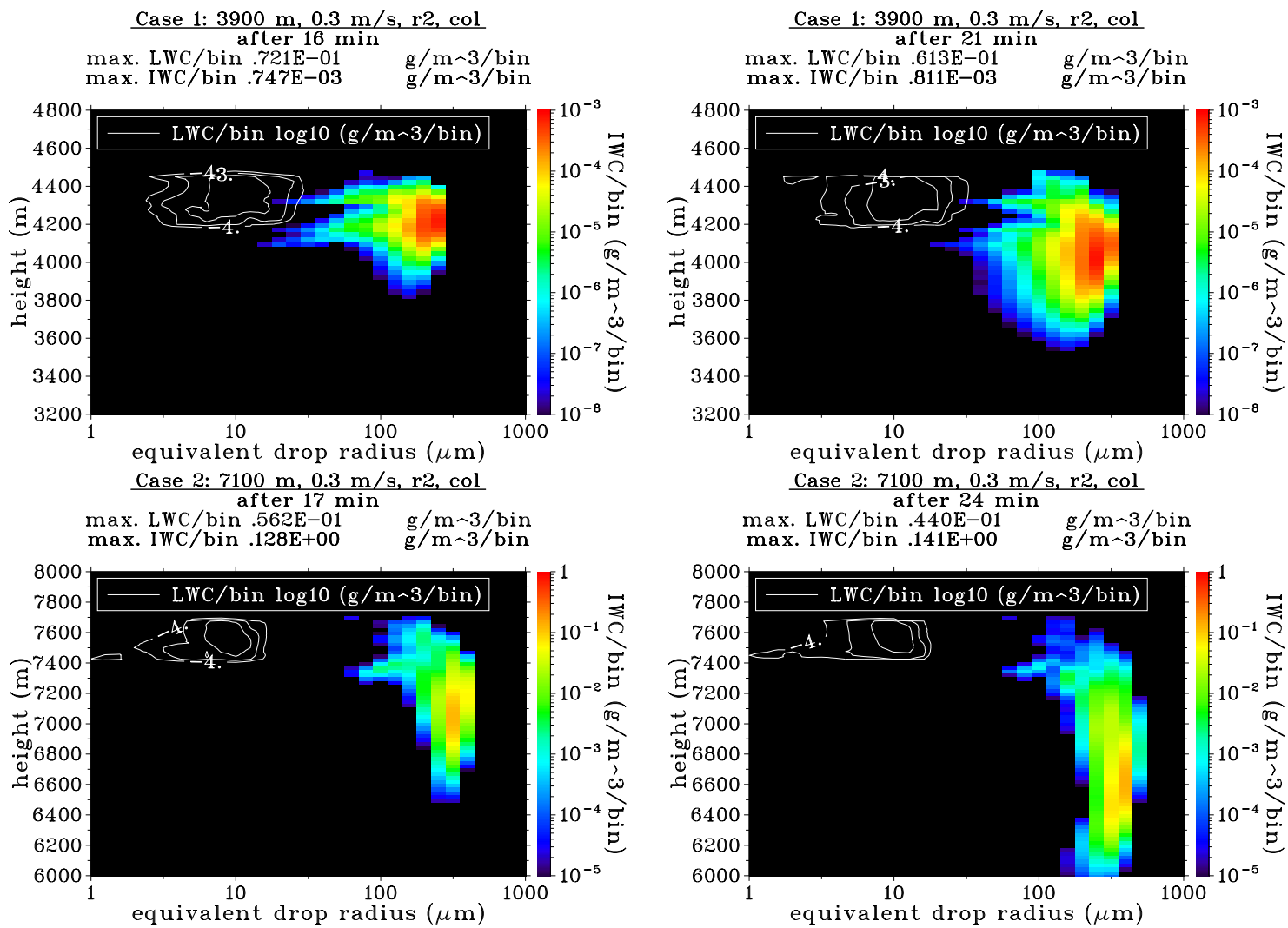

Figure 21. LWC (contours) and ice water mass per bin (colors, both logarithmic scale) for case 1 (upper panel) and case 2 (lower panel) assuming columns as ice particle shape at IWP maximum of the respective base case (left) and at IWP of the run (right).

fers considerably or ice particle shape is different (which should not be the case for relatively similar thermodynamical conditions). After Fukuta and Takahashi (1999) for case 1 with temperatures of about $-6^{\circ} \mathrm{C}$, column-like ice particles with $a r=0.1$ could be expected (corresponding to W_col), whereas for case $2\left(T<-24^{\circ} \mathrm{C}\right)$ hexagonal particles with $a r=1$ are most likely (e.g., C_base). Those ice shapes were observed in laboratory studies at water saturation, which was also valid for the observed cases when ice formed by immersion freezing within the liquid layer of the cloud. However, below liquid cloud base supersaturation with respect to ice decreases. These ice shapes can also explain why a depletion of the liquid phase was not observed in case 2 as it was predicted by the sensitivity studies using either columns or plates as prescribed shape. Generally, the liquid phase is affected considerably only when enough ice particles are 
present, which typically is the case for cold conditions with a sufficient amount of INPs and fast growing ice particle shapes (most effective for large deviations from spherical shapes).

Acknowledgements. This study was supported by the Deutsche Forschungsgemeinschaft (DFG) under grant AN 258/15. We also acknowledge funding from the EU FP7-ENV-2013 programme "impact of Biogenic vs. Anthropogenic emissions on Clouds and Climate: towards a Holistic UnderStanding" (BACCHUS), project no. 603445 .

Edited by: T. Garrett

\section{References}

Althausen, D., Engelmann, R., Baars, H., Heese, B., Ansmann, A., Müller, D., and Komppula, M.: Portable Raman Lidar PollyXT for Automated Profiling of Aerosol Backscatter, Extinction, and Depolarization, J. Atmos. Oceanic Technol., 26, 23662378, 2009.

Asai, T. and Kasahara, A.: A theoretical study of compensating downward motions associated with cumulus clouds, JOURNAL OF THE ATMOSPHERIC SCIENCES, 24, 487-496, 1967.

Bauer-Pfundstein, M. R. and Görsdorf, U.: Target Separation and Classification Using Cloud Radar Doppler-Spectra, in: Proceedings of the 33rd Conference on Radar Meteorology, 2007.

Bergeron, T.: On the physics of clouds and precipitation, in: Proces verbaux de l'association de Météorologie, pp. 156-178, International Union of Geodesy and Geophysics, Lisboa, Portugal, 1935.

Bühl, J., Ansmann, A., Seifert, P., Baars, H., and Engelmann, R.: Toward a quantitative characterization of heterogeneous ice formation with lidar/radar: Comparison of CALIPSO/CloudSat with ground-based observations, Geophys. Res. Lett., 40, 44044408, 2013.

Bühl, J., Engelmann, R., and Ansmann, A.: Removing the LaserChirp Influence from Coherent Doppler Lidar Datasets by TwoDimensional Deconvolution, J. Atmos. Oceanic Technol., 29, 1042-1051, 2012.

Carey, L. D., Niu, J., Yang, P., Kankiewicz, J. A., Larson, V. E., and Vonder Haar, T. H.: The Vertical Profile of Liquid and Ice Water Content in Midlatitude Mixed-Phase Altocumulus Clouds, J. Appl. Meteorol. Climate, 47, 2487-2495, 2008.

Dearden, C., Connolly, P. J., Choularton, T., Field, P. R., and Heymsfield, A. J.: Factors influencing ice formation and growth in simulations of a mixed-phase wave cloud, J. Adv. Model. Earth Syst., 4, M10001, doi:10.1029/2012MS000163, 2012.

DeMott, P. J., Prenni, A. J., Liu, X., Kreidenweis, S. M., Petters, M. D., Twohy, C. H., Richardson, M. S., Eidhammer, T., and Rogers, D. C.: Predicting global atmospheric ice nuclei distributions and their impacts on climate, PROCEEDINGS OF THE NATIONAL ACADEMY OF SCIENCES OF THE UNITED STATES OF AMERICA, 107, 11217-11222, 2010.

Diehl, K., Simmel, M., and Wurzler, S.: Numerical sensitivity studies on the impact of aerosol properties and drop freezing modes on the glaciation, microphysics, and dynamics of clouds, J. Geophys. Res.-Atmos., 111, D07202, doi:10.1029/2005JD005884, 2006.

Eidhammer, T., DeMott, P. J., Prenni, A. J., Petters, M. D., Twohy, C. H., Rogers, D. C., Stith, J., Heymsfield, A., Wang, Z., Pratt, K. A., Prather, K. A., Murphy, S. M., Seinfeld, J. H., Subramanian, R., and Kreidenweis, S. M.: Ice Initiation by Aerosol Particles: Measured and Predicted Ice Nuclei Concentrations versus Measured Ice Crystal Concentrations in an Orographic Wave Cloud, J. Atmos. Sci., 67, 2417-2436, 2010.

Field, P. R., Heymsfield, A. J., Shipway, B. J., DeMott, P. J., Pratt, K. A., Rogers, D. C., Stith, J., and Prather, K. A.: Ice in Clouds Experiment-Layer Clouds, Part II: Testing Characteristics of Heterogeneous Ice Formation in Lee Wave Clouds, J. Atmos. Sci., 69, 1066-1079, 2012.

Findeisen, W.: Kolloid-meteorologische Vorgänge bei Niederschlagsbildung, Meteorolog. Z., 55, 121-133, 1938.

Fleishauer, R. P., Larson, V. E., and Vonder Haar, T. H.: Observed Microphysical Structure of Midlevel, Mixed-Phase Clouds, J. Atmos. Sci., 59, 1779-1804, 2002.

Fridlind, A. M., Ackerman, A. S., McFarquhar, G., Zhang, G., Poellot, M. R., DeMott, P. J., Prenni, A. J., and Heymsfield, A. J.: Ice properties of single-layer stratocumulus during the Mixed-Phase Arctic Cloud Experiment: 2. Model results, J. Geophys. Res.Atmos., 112, D24202, doi:10.1029/2007JD008646, 2007.

Fukuta, N. and Takahashi, T.: The Growth of Atmospheric Ice Crystals: A Summary of Findings in Vertical Supercooled Cloud Tunnel Studies, J. Atmos. Sci., 56, 1963-1979, 1999.

Hartmann, S., Augustin, S., Clauss, T., Wex, H., Santl-Temkiv, T., Voigtlander, J., Niedermeier, D., and Stratmann, F.: Immersion freezing of ice nucleation active protein complexes, Atmos. Chem. Phys., 13, 5751-5766, doi10.5194/acp-13-5751-2013, 2013.

Heymsfield, A. J. and Westbrook, C. D.: Advances in the Estimation of Ice Particle Fall Speeds Using Laboratory and Field Measurements, J. Atmos. Sci., 67, 2469-2482, 2010.

Hogan, R. J., Mittermaier, M. P., and Illingworth, A. J.: The Retrieval of Ice Water Content from Radar Reflectivity Factor and Temperature and Its Use in Evaluating a Mesoscale Model, J. Appl. Meteor. Climatol., 45, 301-317, 2006.

Illingworth, A. J., Hogan, R. J., O’Connor, E. J., Bouniol, D., Delanoë, J., Pelon, J., Protat, A., Brooks, M. E., Gaussiat, N., Wilson, D. R., Donovan, D. P., Baltink, H. K., van Zadelhoff, G.-J., Eastment, J. D., Goddard, J. W. F., Wrench, C. L., Haeffelin, M., Krasnov, O. A., Russchenberg, H. W. J., Piriou, J.-M., Vinit, F., Seifert, A., Tompkins, A. M., and Willén, U.: Cloudnet, Bull. Amer. Meteor. Soc., 88, 883-898, 2006.

Kanitz, T., Seifert, P., Ansmann, A., Engelmann, R., Althausen, D., Casiccia, C., and Rohwer, E. G.: Contrasting the impact of aerosols at northern and southern midlatitudes on heterogeneous ice formation, Geophysical Res. Letters, 38, L17802, doi10.1029/2011GL048532, 2011.

Korolev, A. and Field, P. R.: The Effect of Dynamics on MixedPhase Clouds: Theoretical Considerations, J. Atmos. Sci., 65, 66-86, 2008.

Meyers, M. P., DeMott, P. J., and Cotton, W. R.: New primary icenucleation parameterizations in an explicit cloud model, J. Appl Meteorol., 31, 708-721, 1992. 
Mitchell, D.: Use of mass- and area-dimensional power laws for determining precipitation particle terminal velocities, J. Atmos. Sci., 53, 1710-1723, 1996.

Murray, B. J., O’Sullivan, D., Atkinson, J. D., and Webb, M. E.: Ice nucleation by particles immersed in supercooled cloud droplets, Chem. Soc. Rev., 41, 6519-6554, 2012.

O'Sullivan, D., Murray, B. J., Malkin, T. L., Whale, T. F., Umo, N. S., Atkinson, J. D., Price, H. C., Baustian, K. J., Browse, J., and Webb, M. E.: Ice nucleation by fertile soil dusts: relative importance of mineral and biogenic components, Atmos. Chem. Phys., 14, 1853-1867, 2014.

Petzold, A., Fiebig, M., Flentje, H., Keil, A., Leiterer, U., Schroder, F., Stifter, A., Wendisch, M., and Wendling, P.: Vertical variability of aerosol properties observed at a continental site during the Lindenberg Aerosol Characterization Experiment (LACE 98), J. Geophys. Res.-Atmos., 107, 8128, doi:10.1029/2001JD001043, 2002.

Phillips, V. T. J., DeMott, P. J., and Andronache, C.: An empirical parameterization of heterogeneous ice nucleation for multiple chemical species of aerosol, J. Atmos. Sci., 65, 2757-2783, 2008.

Pospichal, B., Kilian, P., and Seifert, P.: Performance of cloud liquid water retrievals from ground-based remote sensing observations over Leipzig, in: Proceedings of the 9th International Symposium on Tropospheric Profiling (ISTP), 2012.

Shipway, B. J. and Hill, A. A.: Diagnosis of systematic differences between multiple parametrizations of warm rain microphysics using a kinematic framework, Q. J. R. Meteorol. Soc., 138, 21962211, 2012.
Simmel, M. and Wurzler, S.: Condensation and activation in sectional cloud microphysical models, Atmos. Res., 80, 218-236, 2006.

Smith, A. J., Larson, V. E., Niu, J., Kankiewicz, J. A., and Carey, L. D.: Processes that generate and deplete liquid water and snow in thin midlevel mixed-phase clouds, J. Geophys. Res., 114, D12203, 2009.

Sun, J., Ariya, P. A., Leighton, H. G., and Yau, M. K.: Modeling Study of Ice Formation in Warm-Based Precipitating Shallow Cumulus Clouds, J. Atmos. Sci., 69, 3315-3335, 2012.

Warren, S. G., Hahn, C. J., London, J., Chervin, R. M., and Jenne, R.: Global distribution of total cloud cover and cloud type amount over land, Tech. Rep. Tech. Note TN-317 STR, NCAR, 1998a.

Warren, S. G., Hahn, C. J., London, J., Chervin, R. M., and Jenne, R.: Global distribution of total cloud cover and cloud type amount over the ocean, Tech. Rep. Tech. Note TN-317 STR, NCAR, 1998b.

Wegener, A.: Thermodynamik der Atmosphäre, J. A. Barth Verlag, 1911.

Westbrook, C. D., Hogan, R. J., and Illingworth, A. J.: The capacitance of pristine ice crystals and aggregate snowflakes, J. Atmos. Sci., 65, 206-219, 2008. 